Economia e Sociedade, Campinas, Unicamp. IE. http://dx.doi.org/10.1590/1982-3533.2021v30n3art02

\title{
Determinantes para a condição nem-nem dos jovens brasileiros: uma análise desagregada de inativos e desocupados *
}

\author{
Denise Guichard Freire ** \\ João Saboia ${ }^{* * *}$
}

\begin{abstract}
Resumo
O artigo analisa as razões de chance para os jovens brasileiros estarem na condição de nem-nem (não estuda nem trabalha) no período 2004/2015. Para isso utiliza um modelo Logit, desagregando os jovens segundo diversas características pessoais, familiares, domiciliares e geográficas utilizadas na literatura especializada. A principal novidade é separar os nem-nem em dois grupos - inativos e desocupados -, o que permite observar as diferenças entre eles e comparar seus resultados. Assim, o objetivo desse estudo é analisar os determinantes para a condição nem-nem dos jovens no país com o intuito de avaliar: i) os principais determinantes que levam os jovens a estarem nessa condição nem-nem em seu conjunto e nos seus subgrupos de inativos e de desocupados; ii) se houve alteração nesses determinantes entre 2004 e 2014, dadas as mudanças demográficas, econômicas e educacionais ocorridas no período; e iii) se, em 2015, com a crise econômica iniciada em meados de 2014, houve alguma mudança nesses determinantes e na vulnerabilidade social e econômica desses jovens.
\end{abstract}

Palavras-chave: Nem-Nem, Emprego de jovens, Desemprego de jovens, Inatividade de jovens, Escolaridade de jovens.

\begin{abstract}
Determinants for NEET youth in Brazil: a disaggregated analysis of the inactive and unemployed

The article analyzes the reasons why some young people in Brazil are more likely than others to fall into the NEET category (Not in Education, Employment, or Training) in the period 2004/2015. It uses a Logit model, disaggregating the young according to several personal, family, household and geographical characteristics analyzed in the specialized literature. The main difference is the separation of the NEET into two groups - inactive and unemployed -, which allows us to observe the differences between them and compare the results. The objective of this study is to analyze the determinants of the NEET condition in young people in Brazil in order to evaluate: i) the main determinants that lead young people to be NEETs, separating the subgroups into inactive and unemployed; ii) if changes in these determinants occurred between 2004 and 2014 given the demographic, economic and educational changes that occurred in the period; iii) and, if in 2015, due to the economic crisis which started in mid-2014, there was a change in these determinants and in the social and economic vulnerability of young people.
\end{abstract}

Keywords: NEET, Youth employment, Youth unemployment, Youth inactivity, Youth schooling.

JEL: J21, I24, I25.

\section{Introdução}

O jovem estar na condição nem-nem significa estar simultaneamente fora do sistema de ensino e do mercado de trabalho. $\mathrm{O}$ acesso à educação e ao mercado de trabalho são primordiais para garantir o direito ao conhecimento necessário para a sua cidadania e renda para o seu sustento. É uma

\footnotetext{
${ }^{*}$ Artigo recebido em 21 de julho de 2019 e aprovado em 5 de maio de 2021. Os autores agradecem a Paulo Dick pelo apoio na estimação do modelo econométrico.

** Tecnologista sênior da Diretoria de Pesquisas da Fundação Instituto Brasileiro de Geografia e Estatística (IBGE), Rio de Janeiro, RJ, Brasil. E-mail: denisegfreire@gmail.com. ORCID: https://orcid.org/0000-0001-5255-4134.

${ }^{* * *}$ Professor emérito do Instituto de Economia da Universidade Federal do Rio de Janeiro (IE/UFRJ), Rio de Janeiro, RJ, Brasil. E-mail: saboia@ie.ufrj.br. ORCID: https://orcid.org/0000-0003-0509-4723.
} 
fase de transição para a vida adulta, o que torna necessário um olhar atento em busca de compreensão desse fenômeno que atingia cerca de 11 milhões de jovens brasileiros em 2016.

Os estudos iniciais sobre os jovens que nem trabalham e nem estudam no Brasil estavam inseridos dentro de uma análise mais ampla sobre a transição dos jovens entre a saída da escola e o mercado de trabalho. Eles apresentavam informações sobre esses jovens dentro do contexto de análise do mercado de trabalho dos jovens e sua inserção educacional e sobre como era feita a transição escola-trabalho dos jovens. Os que foram realizados exclusivamente sobre esses jovens se iniciaram com o estudo de Camarano et al. (2006), que buscaram compreender as características e os determinantes para a condição nem-nem.

De acordo com o conceito definido internacionalmente, o conjunto de jovens nem-nem ${ }^{1}$ abarca dois subconjuntos: os inativos e os desocupados ${ }^{2}$. Os inativos não estão procurando emprego, enquanto os desocupados o procuram. $\mathrm{Na}$ quase totalidade dos estudos que foram realizados especificamente sobre esses jovens no Brasil, o foco de análise se deteve no subconjunto de jovens nem-nem inativos, justificando, na maioria dos casos, que os jovens desocupados teriam feito a opção pelo mercado de trabalho.

Diferentemente dos trabalhos anteriores, o objetivo desse estudo é analisar os determinantes para a condição nem-nem dos jovens brasileiros com o intuito de avaliar: os principais determinantes que levam os jovens a estar nessa condição nem-nem em sua totalidade e nos seus subgrupos de inativos e de desocupados; se houve alteração nesses determinantes entre 2004 e 2014 dadas as mudanças demográficas, econômicas e educacionais ocorridas no período; e se em 2015, com a crise econômica iniciada em meados de 2014, cresceram as chances desses jovens se manterem nessa condição, dificultando o seu acesso ao mercado de trabalho e aumentando a sua vulnerabilidade social e econômica.

Além dessa breve introdução, o trabalho está divido em três seções: na primeira, é realizada uma resenha sobre os trabalhos que analisaram os determinantes dos jovens nem-nem inativos; na segunda, é apresentada a metodologia do modelo Logit e estimadas as razões de chance de jovens serem nem-nem em sua totalidade e desagregados para os inativos e os desocupados; e, na terceira, são apresentadas as conclusões gerais. Há ainda um anexo estatístico com um conjunto de tabelas com os resultados detalhados dos resultados econométricos obtidos em 2004, 2014 e 2015. Finalmente, no Apêndice é apresentada a documentação das variáveis da PNAD utilizadas no modelo Logit.

\section{Principais estudos realizados no Brasil sobre os determinantes para a condição nem-nem}

Vários estudos têm procurado analisar os determinantes que levam os jovens brasileiros a estar na condição nem-nem. Todos focam a análise nos jovens nem-nem inativos. Serão discutidos a seguir aqueles que consideramos mais importantes para o estudo aqui desenvolvido.

(1) Doravante os jovens que nem trabalham e nem estudam serão denominados como nem-nem.

(2) Ver, por exemplo, De Hoyos; Rogers; Székely (2016), De Hoyos; Popova; Rogers (2016); De Hoyos; Fierros; Vargas (2016); Dennet; Sasser Modestino (2013); Furlong (2007); Furlong; Kelly (2005); O’dea; Glozier; Purcell; McCgorry; Scott; Feilds; Hickie (2014); Ose; Jensen (2017); Serracant (2012); Quintini; Martin; Martins (2007); Cuzzocrea (2014). 
O trabalho de Camarano et al. (2006) foi o pioneiro apontando para as vulnerabilidades e potencialidades advindas do contexto familiar. Os autores focam a análise nos jovens nem-nem inativos de 15 a 29 anos, pois consideram que aqueles que procuram trabalho já fizeram a opção pelo trabalho. Em 2000, havia cerca de 8 milhões de jovens inativos, o que representava $17 \%$ dos jovens não inseridos nem no sistema educacional nem no mercado de trabalho.

Foram analisados jovens a partir de informações dos Censos Demográficos, utilizando um modelo de regressão logística para estimar o impacto de algumas variáveis dos jovens nem-nem em 2000, considerando que idade, sexo, cor/etnia, situação de domicílio, estado conjugal, posição no domicílio, posição social, tamanho das famílias e, no caso das mulheres, maternidade, poderiam ter influência na ampliação ou restrição das possibilidades dos jovens. Para os autores, a família afetaria a constituição identitária e social dos jovens, funcionando como agente promotor de potencialidades ou de acirramento da condição de vulnerabilidade.

Os resultados encontrados mostram que, em 2000, os jovens nem-nem inativos residiam principalmente na zona rural, eram de cor parda, com baixa escolaridade, inseridos em domicílios com maior número de crianças, com renda baixa e chefe de pouca escolaridade. A proporção de mulheres jovens que não estudavam e não trabalhavam era consideravelmente mais elevada que a dos homens. E, ainda, cerca de três quartos delas eram mães e dois terços viviam com um companheiro. Para os autores, esses resultados indicavam que a alocação do tempo dos jovens e, portanto, o processo de transição para a vida adulta apresenta um forte viés de gênero. Em geral, os homens pareciam mais vinculados ao mercado de trabalho e as mulheres ao estudo ou às tarefas domésticas.

O trabalho levou em consideração características de saúde e sociodemográficas do indivíduo. A variável que mostrou o maior impacto na probabilidade de o jovem ser nem-nem, para ambos os sexos, foi a de ser portador de algum tipo de paralisia física, sendo maior entre mulheres e menos educadas. Em contrapartida, entre as variáveis que mais contribuíam para os jovens não pertencerem a esta categoria destaca-se o número de pessoas com renda positiva, o que poderia funcionar como uma proxy da renda domiciliar, além da escolaridade do indivíduo.

O estado conjugal apresentou efeitos importantes, mas com sinais diferentes entre os sexos. Havia maiores chances de ser nem-nem inativo entre os homens solteiros e as mulheres casadas, independentemente do fato de a mulher ter filho ou não. No caso da mãe ser jovem e solteira ou divorciada e ter filhos, a probabilidade de se encontrar nessa condição diminui, ou seja, provavelmente, a mãe que não vive com um companheiro trabalhe para sustentar os filhos.

Reis e Camargo (2007) analisaram os impactos das pensões e aposentadorias sobre a educação e participação dos jovens no mercado de trabalho, dado que esses rendimentos representam uma parcela importante da renda de muitos domicílios no Brasil. O estudo foi realizado a partir dos dados da PNAD 2003, considerando os jovens de 15 a 21 anos, moradores de áreas urbanas. Os resultados apontam no sentido de que em domicílios com rendimentos provenientes de aposentadorias e pensões existe uma maior probabilidade de o jovem somente estudar ou participar do mercado de trabalho e estudar, possibilitando-lhe melhorar o seu capital humano. Contudo, os autores destacam um efeito negativo desses rendimentos, que seria justamente aumentar a proporção de jovens que não participam do mercado de trabalho e não estudam. 
O estudo de Hoffmann (2010) buscou analisar especialmente o resultado do trabalho de Reis e Camargo (2007) sobre a maior proporção de jovens que não estudam e não participam do mercado de trabalho em domicílios com rendimento domiciliar formado por aposentadorias e pensões, a partir das informações da PNAD 2006. Para o autor, ao contrário do estudo anterior, esse tipo de rendimento domiciliar aumenta a probabilidade de o jovem estudar e não participar do mercado de trabalho. Entretanto, não haveria base para afirmar que ele contribui para aumentar a probabilidade de o jovem do domicílio nem estudar e nem participar do mercado de trabalho.

Camarano e Kanso (2012) mostram a situação desfavorável dos jovens de 15 a 29 anos que não trabalham, não estudam e não procuram emprego relativamente aos jovens nas demais situações de atividade e frequência escolar, tendo em vista a vulnerabilidade à qual estão submetidos. $\mathrm{O}$ estudo analisa as informações entre 2000 e 2010 e conclui que para as mulheres, estado conjugal e maternidade são fatores que parecem associados à condição de nem-nem, o que confirmaria uma transição para a vida adulta diferenciada entre os sexos.

As mulheres representam cerca de 7 a cada 10 jovens nem-nem. Em 2010, cerca de 40\% seriam cônjuges e 60\%, mães. Entre os homens, a maioria era solteiro. Esses jovens estavam inseridos em famílias cujo rendimento médio domiciliar per capita era o mais baixo dentre as famílias que tinham jovens nas demais categorias.

Segundo Cardoso (2013), a condição de nem-nem seria um mecanismo gerador de exclusão e desigualdade a longo prazo. Nesse estudo, a maioria dos jovens nem-nem inativos possui baixa escolaridade, pertence a famílias pobres, e cerca de $70 \%$ são mulheres, das quais cerca de $40 \%$ têm filhos. A chance de retornar ao mercado de trabalho e/ou aos estudos é pequena, tendendo a permanecer nesta situação. Para o autor, esta condição é resultado da conjunção de dois conjuntos de determinantes. De um lado, a inserção social dos jovens, que engloba a família, o sistema escolar e o mercado de trabalho e, de outro, as próprias trajetórias dos indivíduos.

Monteiro (2013) aponta também que a condição nem-nem inativa é mais preponderante entre jovens com baixa escolaridade e baixa renda. Em uma análise para jovens entre 19 e 24 anos, o estudo mostra que, em 2011, quase metade dos jovens era formada por mulheres com filhos. A autora considera que ter um filho de menos de 1 ano seria o principal fator para explicar por que as mulheres, especialmente as mais pobres, estavam na condição nem-nem.

O trabalho mostra também que a inatividade havia crescido entre os homens, especialmente entre aqueles com menor nível de escolaridade, indicando que os homens com pouco estudo estariam se afastando do mercado de trabalho. Destaca, ainda, o aumento da inatividade entre jovens com ensino médio, o que seria um dado preocupante tendo em vista que se trata do nível de ensino atingido por muitos dos jovens como um todo, indicando que o aumento da escolaridade traz novos desafios.

Mulheres pobres com bebês apresentavam dez pontos percentuais a mais de chance de estarem na condição nem-nem do que mulheres semelhantes não pobres, o que poderia ser explicado tanto pela falta de creches públicas quanto pelo fato de mulheres de domicílios pobres serem em geral menos educadas e com menor custo de oportunidade de ficarem em casa.

Costa e Ulyssea (2014) analisam as informações dos jovens nem-nem de 15 a 29 anos que não estão na PEA e não frequentam o ensino formal para um período de 20 anos (1992 a 2012). Assim 
como em Camarano e Kanso (2012) e em Monteiro (2013), o estudo mostra que ser mulher, ter filhos, possuir baixa escolaridade e baixa renda domiciliar são características fortemente associadas à propensão a ser nem-nem.

Mediante a decomposição de Oaxaca-Blinder (Oaxaca, 1973; Blinder, 1973), tendo como partida um modelo de probabilidade linear, o estudo apresenta os fatores que explicam a tendência generalizada de queda da proporção de jovens nem-nem no período de 1992 a 2008 e também a entre 2009 e 2012. O resultado aponta que a queda ocorrida entre 1992 e 2008 teve como principal explicação a mudança das características observáveis da população jovem brasileira neste período, como redução da fecundidade e aumento da escolaridade.

Ao considerar o período de 2009-2012, a decomposição mostrou que o efeito-composição novamente atuou no sentido de reduzir a proporção de nem-nem entre os jovens. Neste período, a condição nem-nem se elevou tanto entre os homens como entre as mulheres, principalmente, entre as mulheres com filhos. Assim, o aumento da proporção de nem-nem inativos entre os jovens não teria ocorrido de forma uniforme, tendo sido mais severo entre os indivíduos que poderiam ser considerados mais vulneráveis.

Cabanas et al. (2014) examinaram a situação dos jovens de 15 a 24 anos entre as condições de estudo e trabalho no contexto de redução da taxa de desemprego e alto nível de atividade econômica do país do período. Apesar da melhora no mercado de trabalho de 2004 a 2013, a taxa de participação dos jovens na população economicamente ativa (ocupados ou desocupados) diminuiu, assim como dos jovens que estudam e trabalham. Por outro lado, observaram um aumento na proporção dos jovens que somente estudam e dos jovens nem-nem inativos. Os autores mostram que existe uma forte dependência do comportamento dos jovens em relação à renda domiciliar. Essa influência é ainda maior caso os pais morem no domicílio, ou caso os próprios jovens ou os pais tenham escolaridade mais elevada.

Simulações incluindo interações da renda do jovem com seu nível educacional mostram que os resultados diferem muito para jovens com formação no ensino fundamental ou médio. Entre aqueles sem o fundamental completo, um aumento da renda impacta na redução da participação na PEA e crescimento da dedicação exclusiva aos estudos, mas também da situação nem-nem inativa, o que evidencia a relação da baixa escolaridade com a situação nem-nem. Por outro lado, entre os mais escolarizados, o aumento da renda representa a redução das probabilidades de participação exclusiva na PEA e na situação nem-nem inativa em favor das duas situações de estudos, especialmente aquela associada à participação no mercado de trabalho.

Os autores também notaram a influência positiva para o estudo quando existe a presença de pessoa adulta e/ou idosa no domicílio. Além disso, há impacto positivo da presença de crianças sobre a probabilidade de ser nem-nem inativo, acentuado no caso de haver mais crianças no domicílio. Tal fato pode ser explicado pela necessidade de os jovens cuidarem das crianças presentes não podendo estudar nem ofertar trabalho. A presença dos pais no domicílio também reduz a probabilidade de existência nem-nem inativos, o que mostra a importante influência da estrutura familiar.

Ciríaco et al. (2015) analisa os jovens nem-nem inativos de 18 a 25 anos procurando apontar os principais determinantes da condição nem-nem inativa no país entre os anos de 2002 e 2012 
utilizando um modelo logístico. Os resultados mostram que a existência de outro jovem nem-nem inativo na mesma faixa etária na família tende a aumentar a probabilidade de o jovem estar na condição nem-nem. Além disso, as variáveis de estrutura familiar e escolaridade do jovem também são apontadas como fundamentais na determinação da condição do jovem nem-nem. Mais uma vez é reforçada a ideia de que uma conjuntura familiar favorável é primordial para a redução das taxas de inatividade laboral e educacional entre os jovens.

Tillmann e Comim (2016) analisam os determinantes da decisão dos jovens entre estudo e trabalho, incluídos os jovens nem-nem. O estudo apresenta um modelo logit multinomial com informações da PNAD para o ano de 2011. Ressalta-se que apesar do conceito de jovens nem-nem ter sido utilizado, os resultados são mostrados a partir de duas definições distintas de trabalho. Uma definição é relacionada à ocupação remunerada e outra, mais abrangente, inclui as tarefas domésticas e a ocupação não remunerada.

Segundo os autores, os resultados mostram que na comparação com diferentes conceitos de trabalho, foi possível enfatizar as diferenças entre os sexos. A variável que indica se uma jovem possui filhos, que na definição restrita de trabalho apontava para uma maior probabilidade dela ser nemnem, na definição mais abrangente, indicou maior propensão de estarem apenas trabalhando. Assim, concluem que são necessárias políticas eficientes que permitam às mulheres transferir as responsabilidades de parte das tarefas domésticas, principalmente o cuidado com os filhos, tornando possível uma maior igualdade de oportunidade entre os sexos.

\section{Determinantes para a condição nem-nem dos jovens brasileiros}

O objetivo desta seção é conhecer os principais determinantes para o jovem estar na condição nem-nem e nos seus subgrupos de inativos e de desocupados a partir de um modelo Logit. Para a montagem do modelo Logit foram utilizados os microdados da PNAD nos anos de 2004, 2014 e 2015. $\mathrm{O}$ ano de 2004 foi escolhido por ser o primeiro da nova série com mudança metodológica devido à inclusão de áreas rurais da Região Norte. O ano de 2014 representa a possibilidade de comparação para os determinantes dos jovens nem-nem após uma década de importantes mudanças demográficas, educacionais e econômicas. Enquanto o ano de 2015, por ter sido um ano de forte crise econômica, permite verificar quais mudanças ocorreram nos determinantes em decorrência da crise.

\subsection{Metodologia}

O modelo de regressão logística ou Logit é um modelo de escolha binária, que tem por objetivo o estudo das escolhas de um agente cuja variável dependente possui duas alternativas e a escolha se faz entre uma ou outra (Oliveira, 1998).

Fricker (2016) mostra que esse modelo possibilita interpretar as chances e as razões de chance de um resultado a partir de bases de dados que possuam amostras complexas.

O modelo é descrito com Y representando a resposta em um evento binário e onde $\mathrm{Pi}=\mathrm{Pr}$ $(\mathrm{Yi}=1)$ :

$$
\operatorname{Ln}(\mathrm{Pi} /(1-\mathrm{Pi}))=\beta 0 X+\beta 1 X 1 i+\beta 2 X 2 i+\ldots \ldots+\beta k X k i
$$


O estimador $\beta$ é calculado através do método da máxima verossimilhança

Nesse estudo, $\mathrm{Y}$ representa o conjunto dos jovens nem-nem, sendo $\mathrm{Y}=1$ quando for jovem nem-nem e $Y=0$, caso contrário, e $\exp \not i$ representa a razão de chance do jovem nem-nem em relação ao estado de referência na variável explicativa Xi.

Para a geração das regressões do modelo logístico foram utilizados os microdados da PNAD nos anos de 2004, 2014 e 2015 e o programa R. O Quadro 1 apresenta os totais de unidades domiciliares da amostra com pesquisas realizadas e de pessoas que compunham esses domicílios a cada ano.

Quadro 1

Unidades domiciliares pesquisadas e número de pessoas nos domicílios da PNAD segundo o ano de referência

\begin{tabular}{|c|c|c|}
\hline Ano de referência & Unidades domiciliares & Número de pessoas \\
\hline 2004 & 112.716 & 399.354 \\
\hline 2014 & 119.001 & 362.627 \\
\hline 2015 & 117.939 & 356.904 \\
\hline
\end{tabular}

Fonte: IBGE. Pesquisa Nacional por Amostra de Domicílios (2004, 2014, 2015).

A expansão da amostra utiliza estimadores de razão cuja variável independente é a projeção da população residente de cada Unidade da Federação. A cada ano foram identificados e selecionados os jovens nem-nem entre 15 e 29 anos e todas as pessoas que moravam no mesmo domicílio. As informações dos demais moradores foram utilizadas para contribuir na geração das estatísticas das variáveis explicativas. O objetivo é avaliar os determinantes dos jovens estarem na condição nemnem a partir de um conjunto de variáveis explicativas que envolvem características pessoais, familiares, domiciliares e geográficas.

O Quadro 2 apresenta o número de domicílios em que foram identificados jovens nem-nem entre 15 e 29 anos e o número de jovens nesta condição nestes domicílios pesquisados pela PNAD em 2004, 2014 e 2015.

Quadro 2

Unidades domiciliares com jovens nem-nem de 15 a 29 anos e o número de pessoas identificadas como nem-nem segundo ano de referência

\begin{tabular}{|c|c|c|}
\hline Ano de referência & $\begin{array}{c}\text { Unidades domiciliares em que } \\
\text { havia algum morador de 15 a 29 } \\
\text { anos classificado como nem-nem }\end{array}$ & $\begin{array}{c}\text { Número de pessoas de 15 a 29 anos } \\
\text { classificadas como nem-nem }\end{array}$ \\
\hline 2004 & 19.721 & 22.257 \\
\hline 2014 & 16.166 & 17.807 \\
\hline 2015 & 17.288 & 19.384 \\
\hline
\end{tabular}

Fonte: IBGE. Pesquisa Nacional por Amostra de Domicílios (2004, 2014, 2015).

Para compor o modelo, foram selecionadas as variáveis que mais se destacaram na literatura e na análise empírica apresentadas ao longo desse estudo, a saber: sexo, cor/raça, faixa etária, nível 
de escolaridade, condição na família, presença de filhos, renda domiciliar per capita, presença da mãe no domicílio, dentre outras. A relação das variáveis explicativas é apresentada no Quadro 3.

Quadro 3

Descrição das variáveis explicativas

\begin{tabular}{|c|c|}
\hline Variáveis explicativas & Descrição dos níveis \\
\hline \multirow{2}{*}{ Sexo } & Homem \\
\hline & Mulher \\
\hline \multirow{2}{*}{ Cor/raça } & Brancos \\
\hline & Não-brancos \\
\hline \multirow{6}{*}{ Nível de escolaridade } & Até fundamental incompleto \\
\hline & Fundamental completo \\
\hline & Médio incompleto \\
\hline & Médio completo \\
\hline & Superior incompleto \\
\hline & Superior completo \\
\hline \multirow{3}{*}{ Faixas etárias } & Idade 15 a 17 anos \\
\hline & Idade 18 a 24 anos \\
\hline & Idade 25 a 29 anos \\
\hline \multirow{5}{*}{ Quintos de rendimento domiciliar per capita } & $1^{\circ}$ quinto (mais pobre) \\
\hline & $2^{\circ}$ quinto \\
\hline & $3^{\circ}$ quinto \\
\hline & $4^{\circ}$ quinto \\
\hline & $5^{\circ}$ quinto (mais rico) \\
\hline \multirow{5}{*}{ Condição na família } & Pessoa de referência \\
\hline & Cônjuge \\
\hline & Filho \\
\hline & Outro parente \\
\hline & Não parente \\
\hline \multirow{5}{*}{ Grande Região } & Norte \\
\hline & Nordeste \\
\hline & Sudeste \\
\hline & Sul \\
\hline & Centro-Oeste \\
\hline Mãe viva & Tem mãe viva \\
\hline A mãe mora no domicílio & Mãe mora no domicílio \\
\hline Filhos até 5 anos & Mulheres com filhos até 5 anos \\
\hline Já trabalhou antes & Possui trabalho anterior \\
\hline Outro nem-nem no domicílio & $\begin{array}{l}\text { Existe outro jovem nem-nem inativo } \\
\text { ou desocupado no domicílio }\end{array}$ \\
\hline \multirow{3}{*}{ Crianças no domicílio } & Domicílio com uma criança \\
\hline & Domicílio com duas crianças \\
\hline & Domicílio com três crianças ou mais \\
\hline
\end{tabular}

Na composição da base de dados para a geração das regressões foram adotados os seguintes critérios: 
a) Sexo: os jovens foram classificados por sexo de acordo com a informação da pesquisa, excluindo-se os não identificados;

b) Cor/raça: foram considerados os jovens brancos e os não-brancos. Entre os não-brancos, estão os pretos, os pardos, os amarelos e os indígenas ${ }^{3}$.

c) Nível de escolaridade: os jovens foram agrupados segundo nível de instrução mais alto alcançado no ano de referência. Os grupos "Sem instrução" e "Fundamental incompleto ou equivalente" foram agregados em 'até ensino fundamental incompleto'.

d) Quintos de rendimento domiciliar per capita: a amostra foi classificada em percentis de acordo com o rendimento domiciliar per capita, e, posteriormente, agregada em quintos. A classificação foi feita usando uma lógica de pesos acumulados, ou seja: a base foi ordenada pelo rendimento domiciliar per capita, para em seguida definir o percentil 1 como o conjunto de registros para os quais a soma dos pesos era menor que $1 \%$ da soma total dos pesos.

Para minimizar o efeito da ordenação geográfica da base (pois as Unidades da Federação da região Norte aparecem primeiro), ela foi randomizada, para posteriormente ser ordenada por ordem crescente de rendimento domiciliar per capita. Em seguida, os domicílios foram filtrados à medida que atingiam os quintos de seleção.

A necessidade de randomização da base de dados se justifica devido à presença de empates na variável rendimento domiciliar per capita. Ela elimina o efeito da ordenação geográfica existente na base, de forma que se não fosse aplicada haveria sistematicamente a classificação de pessoas das regiões Norte e Nordeste como mais pobres. A randomização preliminar da base (não dos domicílios) é feita para minimizar este impacto.

a) Condição na família: os jovens foram analisados a partir da sua condição na família à qual fazem parte; 'Outro parente' e 'agregado' foram agregados como 'outro parente' e 'Pensionista', 'Empregado doméstico' e 'Parente do empregado doméstico' foram agregados como 'não parente'.

b) Tem mãe viva: para avaliar essa variável, foi considerado $X=1$, em caso positivo e $X=0$, caso contrário.

c) A mãe mora no domicílio: Nesse caso, foi considerado $X=1$, caso houvesse a presença da mãe e $\mathrm{X}=0$, caso contrário.

d) Filhos até 5 anos: essa variável é calculada exclusivamente para mulheres jovens que tenham filhos ${ }^{4}$ a partir das informações do bloco de fecundidade. Homens receberam automaticamente valor zero.

e) Já trabalhou antes: o objetivo dessa variável é avaliar se o jovem já fez parte do mercado de trabalho alguma vez, sendo $X=1$ caso tenha trabalhado e $X=0$, caso contrário.

\footnotetext{
(3) Os amarelos por terem características mais próximas dos brancos poderiam ter sido agregados aos brancos, mas optou-se por separar os brancos dos não-brancos. Como eles são pouco numerosos modificam pouco os resultados.

(4) Inicialmente, utiliza-se uma variável auxiliar sobre a existência ou não de filhos em mulheres. Posteriormente, utiliza-se outra variável para conhecer a idade dos filhos para aquelas que afirmaram possuir filhos. Mulheres sem filhos e homens são desconsiderados no cálculo dessa variável.
} 
f) Nem-Nem no domicílio: nessa variável se considera a existência de outro jovem nemnem no domicílio, seja inativo ou desocupado, sendo $X=1$ caso tenha e $X=0$, caso contrário.

g) Crianças no domicílio: número de crianças até 5 anos existentes no domicílio, independentemente de serem filhos. Nesse caso, a variável pode ser considerada para homens e para mulheres.

Nesse estudo, além do cálculo das razões de chances do jovem nem-nem na sua totalidade, são estimadas as razões para os subgrupos de inativos e de desocupados considerando as mesmas variáveis explicativas para os anos de 2004, 2014 e 2015. O intuito é verificar se existem diferenças relevantes para a condição nem-nem na sua totalidade e nos seus subgrupos ao longo deste período, com o objetivo de identificar como determinados aspectos podem influenciar nessa condição e como eles atuam em período de crise.

\subsection{Resultados}

Antes da apresentação dos resultados do modelo serão informados alguns dados para dimensionar o estoque de jovens nem-nem de 15 a 29 anos e sua evolução no período 2004/2015. Além disso, tais dados são desagregados segundo os dois grupos utilizados no estudo: nem-nem inativos; nem-nem desocupados.

Conforme pode ser verificado no Gráfico 1, enquanto o número total de jovens se reduziu por conta da transição demográfica do país, especialmente a partir de 2011, a população nem-nem (inativos e desocupados) permaneceu relativamente estável na maior parte do período, aumentando somente em 2015, ano de forte queda do PIB. Os jovens de 15/29 anos passaram de 50 para 48,3 milhões entre 2004 e 2015. Os jovens nem-nem aumentaram de 9,9 para 10,9 milhões no mesmo período.

Gráfico 1

Evolução do número de jovens e de jovens nem-nem - Brasil - 2004-2015

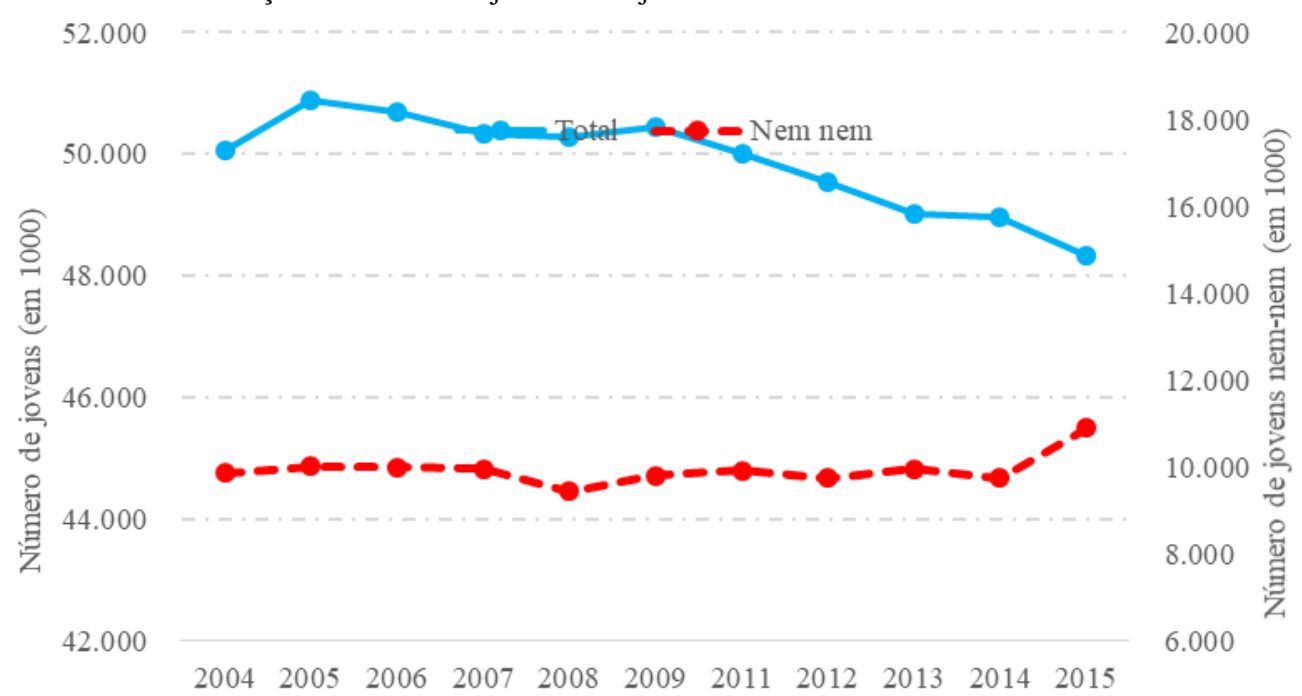

Fonte: Elaboração dos autores a partir dos microdados da PNAD. 
Houve aumento da taxa de jovens nem-nem de $19,7 \%$ para $22,5 \%$ no período. Note-se, entretanto, que a maior parte do crescimento da taxa ocorreu entre 2014 e 2015 . Outro fato notável é a taxa feminina, inicialmente quase o triplo da masculina, baixando para o dobro em 2015. Ao longo do período analisado, houve contínuo crescimento da taxa de jovens nem-nem entre os homens. Em 2015 ela atingia $15,4 \%$ para os homens e $29,8 \%$ para as mulheres (ver Gráfico 2).

Gráfico 2

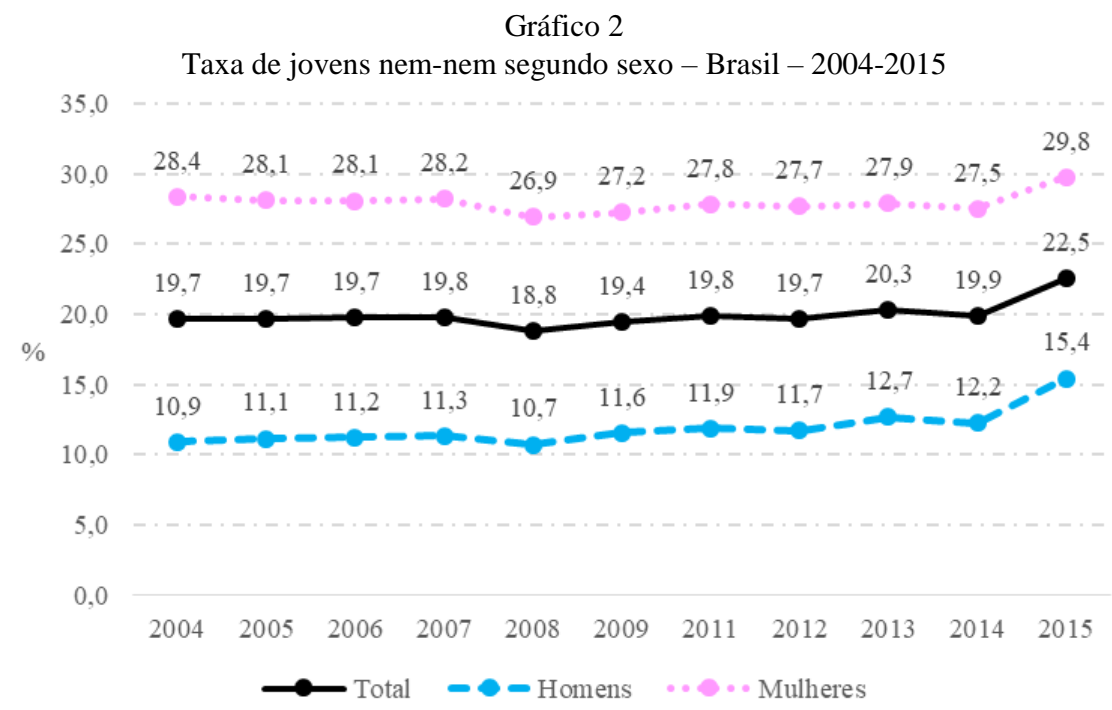

Fonte: Elaboração dos autores a partir dos microdados da PNAD.

Grosso modo, a população nem-nem é composta por 30\% de desocupados e $70 \%$ de inativos. Considerando-se todo o período, tanto a taxa de nem-nem inativos quanto a de desocupados apresentaram tendência de elevação. Tal crescimento, entretanto, foi muito mais elevado para os desocupados, especialmente no último ano. Em 2015, quando a taxa de jovens nem-nem era 22,5\%, a de inativos atingia $14,4 \%$, a de desocupados, $8,1 \%$ (ver Gráfico 3).

Gráfico 3

Taxa de jovens nem-nem segundo condição de atividade - Brasil - 2004-2015

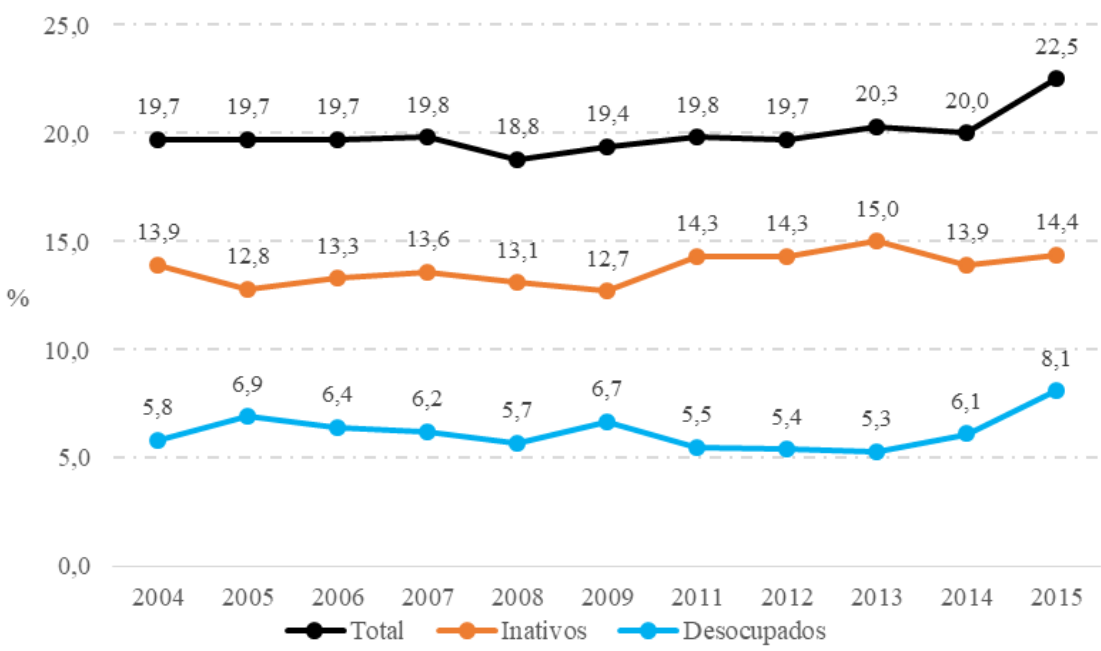

Fonte: Elaboração dos autores a partir dos microdados da PNAD. 


\subsubsection{Jovens nem-nem inativos}

A Tabela 1 apresenta um panorama geral dos resultados das razões de chance do modelo Logit. As razões foram calculadas a partir da subtração de uma unidade das razões de chance (exp $\beta$ ) dos resultados apresentados nas Tabelas A1 a A9 do Anexo e posterior multiplicação por 100 para apresentação dos resultados em porcentagem. O objetivo é mostrar de forma comparativa as principais similaridades e as diferenças entre os determinantes dos jovens nem-nem nos subgrupos de inativos e de desocupados e avaliar as vulnerabilidades em cada grupo.

Tabela 1

Razões de chance (\%) dos jovens nem-nem segundo variáveis selecionadas - Brasil - 2004/2014/2015

\begin{tabular}{|c|c|c|c|c|c|c|c|c|c|c|}
\hline \multirow{2}{*}{\multicolumn{2}{|c|}{ Variáveis selecionadas }} & \multicolumn{3}{|c|}{ Nem-nem inativo } & \multicolumn{3}{|c|}{ Nem-nem desocupado } & \multicolumn{3}{|c|}{ Nem-nem } \\
\hline & & \multirow{3}{*}{$\begin{array}{c}2004 \\
-\end{array}$} & \multirow{3}{*}{$\begin{array}{c}2014 \\
- \\
39,4\end{array}$} & \multirow{3}{*}{$\begin{array}{c}2015 \\
- \\
49,2\end{array}$} & \multirow{3}{*}{$\begin{array}{c}2004 \\
- \\
-10,1\end{array}$} & \multirow{3}{*}{$\begin{array}{c}2014 \\
- \\
0,0\end{array}$} & \multirow{3}{*}{$\begin{array}{c}2015 \\
- \\
-10,5\end{array}$} & \multirow{3}{*}{$\begin{array}{c}2004 \\
- \\
18,8 \\
\end{array}$} & \multirow{3}{*}{$\begin{array}{c}2014 \\
- \\
27,1\end{array}$} & \multirow{3}{*}{$\begin{array}{c}2015 \\
- \\
22,9\end{array}$} \\
\hline & Homem & & & & & & & & & \\
\hline & Mulher & & & & & & & & & \\
\hline \multirow{2}{*}{ Cor ou raça } & Branco & - & - & - & - & - & - & - & - & - \\
\hline & Não-branco & $-4,5$ & $-1,4$ & $-3,4$ & 14,3 & 12,6 & 11,6 & 4,5 & 7,1 & 6,7 \\
\hline \multirow{6}{*}{$\begin{array}{l}\text { Nível de } \\
\text { instrução }\end{array}$} & $\begin{array}{c}\text { Até EF } \\
\text { incompleto }\end{array}$ & - & - & - & - & - & - & - & - & - \\
\hline & EF completo & $-45,4$ & $-43,6$ & $-41,9$ & 27,0 & 8,2 & 29,1 & $-33,1$ & $-37,3$ & $-27,4$ \\
\hline & EM incompleto & $-75,1$ & $-70,2$ & $-70,4$ & $-27,5$ & $-10,7$ & $-9,5$ & $-75,6$ & $-69,4$ & $-69,0$ \\
\hline & EM completo & $-24,1$ & $-19,6$ & $-26,4$ & 186,5 & 104,1 & 141,0 & 66,2 & 29,2 & 49,6 \\
\hline & ES incompleto & $-91,4$ & $-92,0$ & $-92,7$ & $-56,7$ & $-61,4$ & $-62,7$ & $-89,8$ & $-92,8$ & $-93,0$ \\
\hline & ES completo & $-20,4$ & $-43,9$ & $-51,9$ & 158,8 & 218,1 & 236,7 & 53,8 & 28,6 & 34,1 \\
\hline \multirow{3}{*}{ Faixa etária } & 15 a 17 anos & $-70,2$ & $-80,5$ & $-81,6$ & $-75,8$ & $-78,1$ & $-83,1$ & $-83,6$ & $-89,7$ & $-91,8$ \\
\hline & 18 a 24 anos & $-0,2$ & $-8,2$ & $-8,5$ & 14,2 & 19,2 & 15,0 & 9,1 & 3,5 & 1,6 \\
\hline & 25 a 29 anos & - & - & - & - & - & - & - & - & - \\
\hline \multirow{5}{*}{$\begin{array}{l}\text { Quintos de } \\
\text { rendimento } \\
\text { domiciliar } \\
\text { per capita } \\
\text { (em SM) }\end{array}$} & $1^{\circ}$ quinto & 89,0 & 82,4 & 67,3 & 335,4 & 440,1 & 467,4 & 334,7 & 327,0 & 375,2 \\
\hline & $2^{\circ}$ quinto & 71,2 & 86,4 & 54,0 & 218,0 & 294,2 & 331,3 & 221,0 & 237,4 & 244,9 \\
\hline & $3^{\circ}$ quinto & 60,0 & 54,5 & 38,7 & 153,8 & 144,2 & 228,8 & 163,1 & 118,0 & 161,4 \\
\hline & $4^{\circ}$ quinto & 24,0 & 24,8 & 9,3 & 81,0 & 65,1 & 77,0 & 74,3 & 53,6 & 50,7 \\
\hline & $5^{\circ}$ quinto & - & - & - & - & - & - & - & - & - \\
\hline \multirow{4}{*}{$\begin{array}{c}\text { Condição no } \\
\text { domicílio }\end{array}$} & Referência & - & - & - & - & - & - & - & - & - \\
\hline & Cônjuge & 241,1 & 99,7 & 87,6 & 2,3 & $-12,2$ & $-10,0$ & 178,6 & 66,3 & 57,8 \\
\hline & Filho & $-19,0$ & $-20,7$ & $-16,7$ & $-11,9$ & $-12,7$ & $-15,1$ & $-29,1$ & $-27,9$ & $-26,4$ \\
\hline & $\begin{array}{c}\text { Outro parente / } \\
\text { agregado }\end{array}$ & $-20,0$ & $-36,3$ & $-37,1$ & $-1,2$ & $-20,9$ & $-27,4$ & $-26,6$ & $-44,9$ & $-49,9$ \\
\hline \multirow{5}{*}{$\begin{array}{l}\text { Grande } \\
\text { Região }\end{array}$} & Norte & $-7,5$ & $-25,5$ & $-18,1$ & $-43,5$ & $-20,5$ & $-38,6$ & $-32,1$ & $-34,7$ & $-38,8$ \\
\hline & Nordeste & $-20,2$ & $-18,2$ & $-13,5$ & $-34,3$ & $-12,5$ & $-25,8$ & $-37,6$ & $-24,6$ & $-28,2$ \\
\hline & Sudeste & $-12,5$ & $-12,4$ & $-23,1$ & 19,2 & 40,5 & 33,8 & 0,8 & 8,3 & 0,6 \\
\hline & Sul & 8,6 & 1,6 & $-11,1$ & 0,1 & 13,1 & 18,1 & 7,7 & 7,6 & 3,7 \\
\hline & Centro-Oeste & - & - & - & - & - & - & - & - & - \\
\hline $\begin{array}{c}\text { Tem mãe } \\
\text { viva }\end{array}$ & Sim & $-12,0$ & $-0,2$ & $-5,4$ & 7,0 & $-4,9$ & 8,1 & $-8,0$ & $-5,3$ & $-1,6$ \\
\hline
\end{tabular}

Continua... 
Determinantes para a condição nem-nem dos jovens brasileiros: uma análise desagregada de inativos e desocupados

Tabela 1 - Continuação

\begin{tabular}{|c|c|c|c|c|c|c|c|c|c|c|}
\hline \multirow{2}{*}{\multicolumn{2}{|c|}{ Variáveis selecionadas }} & \multicolumn{3}{|c|}{ Nem-nem inativo } & \multicolumn{3}{|c|}{ Nem-nem desocupado } & \multicolumn{3}{|c|}{ Nem-nem } \\
\hline & & \multirow{2}{*}{$\begin{array}{r}2004 \\
-22,8\end{array}$} & \multirow{2}{*}{$\begin{array}{r}2014 \\
-32,1\end{array}$} & \multirow{2}{*}{$\begin{array}{r}2015 \\
-30,4\end{array}$} & \multirow{2}{*}{$\begin{array}{l}2004 \\
-19,1\end{array}$} & \multirow{2}{*}{$\begin{array}{r}2014 \\
-9,8\end{array}$} & \multirow{2}{*}{$\begin{array}{l}2015 \\
-10,9\end{array}$} & \multirow{2}{*}{$\begin{array}{l}2004 \\
-28,5\end{array}$} & \multirow{2}{*}{$\begin{array}{r}2014 \\
-31,4\end{array}$} & \multirow{2}{*}{$\begin{array}{r}2015 \\
-31,5\end{array}$} \\
\hline $\begin{array}{c}\text { Mãe mora } \\
\text { no domicílio }\end{array}$ & Sim & & & & & & & & & \\
\hline $\begin{array}{c}\text { Filhos de até } \\
5 \text { anos }\end{array}$ & Sim & 120,6 & 239,8 & 214,6 & 35,9 & 24,7 & 4,0 & 163,1 & 271,0 & 213,8 \\
\hline $\begin{array}{c}\text { Já trabalhou } \\
\text { antes }\end{array}$ & Sim & $-94,5$ & $-95,3$ & $-94,5$ & $-71,7$ & $-63,7$ & $-64,5$ & $-95,8$ & $-96,2$ & $-95,8$ \\
\hline $\begin{array}{c}\text { Nem-nem } \\
\text { no domicílio }\end{array}$ & Sim & 321,5 & 307,3 & 261,0 & 366,0 & 289,8 & 271,4 & 740,1 & 696,2 & 672,8 \\
\hline \multirow{4}{*}{$\begin{array}{c}\text { Crianças no } \\
\text { domicílio }\end{array}$} & 0 & - & - & - & - & - & - & - & - & - \\
\hline & 1 & $-9,2$ & $-21,5$ & $-21,9$ & $-22,8$ & $-26,8$ & $-21,7$ & $-23,7$ & $-34,0$ & $-32,8$ \\
\hline & 2 & $-12,3$ & $-12,0$ & $-20,2$ & $-26,2$ & $-40,4$ & $-29,7$ & $-25,8$ & $-34,7$ & $-34,2$ \\
\hline & 3 ou mais & $-11,2$ & $-2,2$ & $-4,3$ & $-33,5$ & $-57,4$ & $-29,7$ & $-26,6$ & $-38,4$ & $-15,9$ \\
\hline
\end{tabular}

Nota: Os resultados com células sombreadas não foram significativos ao nível de $5 \%$.

Fonte: Elaboração dos autores a partir da Pesquisa Nacional por Amostra de Domicílios (2004, 2014, 2015).

Os resultados do Modelo Logit para os jovens nem-nem inativos nos anos de 2004, 2014 e 2015 são apresentados nas Tabelas A1 a A3 do Anexo. Observa-se que a maioria dos coeficientes estimados é significativa, exceto para cor/raça, para a Região Sul e para ter três ou mais crianças no domicílio.

A mulher apresentava maior chance de ser nem-nem inativo do que o homem. Entre $2004 \mathrm{e}$ 2014, essa chance diminuiu de $47 \%$ para $39 \%$, aumentando para $49 \%$ em 2015 , ano de início da crise econômica. Esse resultado decorre principalmente das diferenças nas atribuições por gênero na sociedade brasileira, que atribui à mulher a maior parte do trabalho não remunerado, ou seja, das tarefas domiciliares e no cuidado de parentes.

Em relação à escolaridade, os resultados mostram que em todos os níveis de escolaridade há uma menor chance de ser nem-nem do que o jovem com ensino fundamental incompleto. Contudo não existe uma linearidade. Jovens com ensino médio completo e com ensino superior completo possuem relativamente mais chances de ser nem-nem do que os jovens nos demais níveis de escolaridade. Isso ocorre provavelmente porque muitos jovens depois de formados possuem dificuldades para se inserir no mercado pela falta de experiência e devido às obrigações domiciliares e familiares, sendo que alguns podem optar por permanecer fora do mercado de trabalho. Observase, contudo, que a chance de um jovem com ensino superior completo ser nem-nem inativo tem sido cada vez menor. Era 20\% menor que o de referência em 2004, reduziu para 44\% menor em 2014 e para 52\% menor em 2015.

Por faixa etária, os jovens entre 15 e 17 anos possuem menores chances que os demais de serem nem-nem inativos. Tal fato seria esperado até porque por serem mais jovens ainda se encontram no período de maior frequência escolar. Ressalte-se, ainda, que essa chance diminuiu em comparação com os jovens de 25 a 29 anos (referência) entre 2004 e 2014, de $70 \%$ menor para $80 \%$ menor, mantendo-se nesse patamar em 2015. Por sua vez, os jovens entre 18 e 24 anos possuíam as mesmas chances de serem nem-nem inativos em comparação com os jovens de referência. 
O rendimento domiciliar apresenta uma forte influência em o jovem ser nem-nem inativo, pois quanto maior o nível de rendimento, menor a chance em relação ao jovem nem-nem do domicílio de maior renda ( $5^{\circ}$ quinto). Em 2004, o jovem do domicílio mais pobre, que estava no $1^{\circ}$ quinto, apresentava $89 \%$ mais chances do que o do mais rico; no $2^{\circ}$ quinto a chance se reduzia para $71 \%$ a mais; no $3^{\circ}$ quinto para $60 \%$ e no $2^{\circ}$ quinto para $24 \%$. Há claramente uma relação inversa. Em 2014 , as chances mantiveram-se nesse patamar, tendo sido observado crescimento apenas no $2^{\circ}$ quinto que passou a ter $86 \%$ mais de chance. Por sua vez, em 2015, as chances de os jovens manterem-se como inativos diminuíram em todos os níveis de rendimento relativamente ao grupo de referência. Isso talvez esteja associado à busca pelo mercado de trabalho no início da crise econômica, pois a necessidade de compor a renda domiciliar pelos jovens se torna maior devido à diminuição da renda dos responsáveis pelo domicílio.

Por condição na família, o jovem cônjuge é o que apresenta maior chance de ser nem-nem inativo em relação à pessoa de referência no domicílio. Entretanto, houve uma redução significativa na sua chance entre 2004 e 2014, tendo passado de 241\% maior para 100\%. Em 2015, diminuiu ainda mais, para $88 \%$. Todas as demais condições, possuem chances menores do que a pessoa de referência. Ser filho permaneceu com chances cerca de $20 \%$ menores que a pessoa de referência no domicílio em todos os anos. Deve-se esperar que boa parte dos filhos ainda esteja estudando, o que reduz sua probabilidade de inatividade.

Os resultados por Grande Região demonstraram que os jovens das Regiões Norte, Nordeste e Sudeste possuem menos chances de serem inativos do que os da Região Centro-Oeste. Na Região Sul os resultados não foram significativos.

Ter mãe viva diminuiu a chance de o jovem ser nem-nem inativo em todos os anos em análise. Se a mãe morar no domicílio, as chances são ainda menores, tendo sido $23 \%$ a menos do que para aqueles jovens que não moram com a mãe em 2004, 32\% a menos em 2014 e 30\% em 2015. Portanto, a presença da mãe contribui positivamente para que o jovem não esteja na condição nem-nem inativa, estimulando-o a participar do sistema de ensino e/ou ir em busca de uma colocação no mercado de trabalho.

A maternidade, por outro lado, aumenta significativamente as chances da jovem ser nem-nem inativa. Em 2004, as jovens com filhos até 5 anos possuíam 121\% mais chances do que as que não possuíam filhos pequenos. Em 2014, essa chance havia aumentado para 240\%, e em 2015 foi de $215 \%$. Ou seja, é cada vez maior a chance de inatividade da jovem com filhos pequenos. A falta de estrutura familiar que apoie a jovem na manutenção de suas atividades estudantis e laborais, assim como a falta de oferta suficiente de creches e escolas infantis públicas, contribuem para esse quadro. Ainda é muito baixo o percentual de crianças até cinco anos que frequenta creche ou educação infantil.

Caso o jovem já tenha trabalhado anteriormente, e já possua experiência profissional, as chances de ser nem-nem inativo é muito pequena. Em todos os anos analisados, os jovens com experiência possuíam $95 \%$ menores chances de ser nem-nem do que os jovens sem experiência.

Ter outro jovem nem-nem inativo no domicílio aumenta significativamente a chance de o jovem também ser nem-nem inativo, embora essa chance venha se reduzindo. Esse resultado parece demonstrar que a condição nem-nem pode estar relacionada em algumas situações a ofertas 
insuficientes de ensino e de emprego para os jovens, gerando um ambiente propício à ausência do jovem no estabelecimento de ensino e na população economicamente ativa simultaneamente. Em 2004, o jovem nem-nem que tivesse outro jovem nem-nem no seu domicílio possuía $321 \%$ mais chances de estar inativo do que o jovem que não tivesse. Em 2014, a chance havia se reduzido pouco para $307 \%$ e, em 2015, para 261\%. De qualquer forma, um patamar extremamente elevado.

Finalmente, o número de crianças no domicílio, porém, apresentou como resultado uma menor chance de o jovem ser nem-nem inativo. O que pode significar que as despesas com as crianças obriguem os jovens a buscar uma ocupação, não podendo permanecer na inatividade. Ressalta-se que nesse caso estamos tratando de jovens homens e mulheres, enquanto a presença de filhos até 5 anos contempla somente as jovens mulheres.

Como apresentado na primeira seção, os estudos previamente realizados que analisaram os determinantes para a condição nem-nem dos jovens brasileiros se concentravam principalmente nos jovens nem-nem inativos. Os resultados apresentados pelo modelo Logit vão, de uma maneira geral, ao encontro aos apresentados em estudos anteriores, com exceção dos resultados regionais e em relação à presença de crianças no domicílio. Cardoso (2013) havia apontado uma maior prevalência de jovens inativos nas regiões Norte e Nordeste em relação à região Centro-Oeste. Nos resultados do modelo Logit, contudo, as regiões Norte e Nordeste não apresentavam maiores chances do que a Centro-Oeste.

Cabanas et al. (2014) mostraram uma influência positiva quando existe a presença do adulto no domicílio, confirmando os resultados do modelo. Contudo, haveria um impacto negativo da presença de crianças sobre as probabilidades de o jovem ser nem-nem, acentuando-se no caso de haver mais crianças no domicílio. No resultado deste modelo, entretanto, o impacto da presença de crianças foi positivo, o que pode significar a necessidade de uma maior renda e a impossibilidade do jovem se manter inativo.

\subsubsection{Jovens nem-nem desocupados}

Os resultados do Modelo Logit para os jovens nem-nem desocupados nos anos de 2004, 2014 e 2015 são apresentados nas Tabelas A4 a A6 do anexo. Observa-se que a maioria dos coeficientes estimados é significativa ${ }^{5}$.

Em relação à escolaridade, os jovens com ensino fundamental completo, ensino médio completo e ensino superior completo possuem maiores chances de ser nem-nem desocupado do que os jovens com ensino fundamental incompleto. Isso pode ser explicado pela maior possibilidade que aqueles jovens possuem em se inserir no mercado de trabalho do que esses, dado o seu baixo nível de escolaridade. Os jovens com ensino fundamental incompleto têm maior chance de ser um nem-nem inativo do que um nem-nem desocupado na comparação com os outros níveis de escolaridade.

Por faixa etária, os jovens entre 15 e 17 anos possuem menores chances que os demais de serem nem-nem desocupados, assim como nem-nem inativos, provavelmente por ainda estarem

(5) Exceto para sexo, cor/raça, condição de domicílio como cônjuge, o fato de ter mãe viva, níveis de instrução fundamental completo em 2004 e 2014 e superior incompleto em 2004 e 2015, para a Região Sul em 2004 e 2014 e presença de filhos até cinco anos em 2015. 
estudando e fora do mercado de trabalho. Por sua vez, os jovens entre 18 e 24 anos possuíam maiores chances de estar desocupados do que os jovens de 25 a 29 anos. Situação inversa à apresentada pelos jovens nem-nem inativos, pois os jovens de 25 a 29 anos teriam maiores chances de estarem naquela condição.

O rendimento domiciliar apresenta também uma forte influência de o jovem ser nem-nem desocupado, pois quanto menor o nível de rendimento maior a chance em relação ao jovem nem-nem do domicílio mais rico ( $5^{\circ}$ quinto). Ressaltando-se que as chances nesse caso são muito mais elevadas por nível de rendimento do que entre os nem-nem inativos. O efeito renda nesse caso demonstra ser mais forte do que entre os jovens inativos. Conforme esperado, o menor nível de rendimento do domicílio induz os jovens à busca de um emprego, passando pela situação de desemprego.

Em 2004, o jovem do domicílio mais pobre, que estava no $1^{\circ}$ quinto, apresentava $335 \%$ mais de chance do que o do jovem do $5^{\circ}$ quinto de ser um nem-nem desocupado. Para o jovem do $2^{\circ}$ quinto a chance ainda era bem elevada, $218 \%$, no $3^{\circ}$ quinto era $154 \%$ e no $2^{\circ}$ quinto era $81 \%$. Em 2014 , as chances aumentaram para os jovens dos domicílios mais pobres, do $1^{\circ}$ e do $2^{\circ}$ quinto, enquanto para os demais mantiveram-se em patamares próximos. Em 2015, as chances aumentaram ainda mais para os vários quintos, confirmando a necessidade de busca de emprego para os jovens mais pobres em momento de crise.

Por condição na família, apesar de alguns problemas na significância em alguns casos, de uma maneira geral observa-se que todas as condições de domicílio (cônjuge, filho, outro parente, não parente) apresentam menores chance de ser jovem nem-nem desocupado do que o jovem na condição de referência. Entre os jovens inativos, a chance era maior para o cônjuge. O jovem que é referência no domicílio se lançaria na busca por um emprego, enquanto o cônjuge teria mais condições de permanecer na condição de inatividade pois eventualmente outra pessoa seria responsável por sustentar o domicílio.

Em 2004, os resultados por Grande Região demonstraram que os jovens das regiões Sudeste e Sul apresentam maiores chances de ser nem-nem desocupado do que na Região Centro-Oeste (região de referência) e nas Regiões Norte e Nordeste. Em 2014, as chances aumentaram em todas as regiões, permanecendo no mesmo patamar em 2015. Os jovens da Região Sudeste e Sul tinham $34 \%$ e 18\% mais chances, respectivamente, de ser nem-nem desocupado do que na região Centro-Oeste, em 2015. Por outro lado, nas Regiões Norte e Nordeste, as chances eram 39\% e $26 \%$ menores. Talvez o próprio fato de terem mercados de trabalho mais desenvolvidos facilite a busca de emprego pelos jovens provocando a maior chance de jovens se encontrarem na situação de nem-nem desocupado nas regiões Sul e Sudeste.

A mãe morar no domicílio reduz as chances de o jovem ser nem-nem desocupado em relação ao jovem que não mora com a mãe. Em 2004, a chance diminuía em 19\% e em 2015 em 11\%, resultado semelhante ao encontrado no caso do jovem nem-nem inativo.

Por sua vez, a maternidade aumenta significativamente as chances da jovem ser nem-nem desocupada do que para a jovem que não possui filhos. Contudo, essas chances diminuíram e estão em um patamar inferior ao das jovens inativas e se reduziram entre 2004 e 2014. 
Em 2004, as jovens com filhos até 5 anos possuíam 36\% mais chances do que as que não possuíam filhos pequenos. Em 2014, essa chance havia diminuído para 25\%. Em 2015 o resultado não é significativo. Entre as jovens inativas, as chances eram muito mais elevadas e aumentaram entre os anos analisados.

A existência de crianças no domicílio apresentou como resultado uma maior chance do jovem, homem ou mulher, ser nem-nem desocupado em comparação com o jovem que não possui crianças no domicílio. O que pode significar que crianças no domicílio forcem as jovens a irem em busca de um emprego por necessidade de uma renda maior para cobrir as despesas. As dificuldades de inserção, entretanto, podem deixar tais jovens na situação de desempregados por algum tempo.

O jovem que já tenha trabalhado anteriormente vê reduzidas suas chances de ser nem-nem desocupado em relação ao jovem sem experiência profissional. As chances para os jovens com experiência variaram pouco no período, em torno de $70 \%$. Esse é um resultado importante, que demonstra como já ter participado do mercado de trabalho anteriormente reduz as chances de o jovem estar na condição de nem-nem desocupado. Entre os inativos, o resultado foi ainda mais forte com cerca de $95 \%$ menos de chance para o jovem com experiência.

Ter outro jovem nem-nem aumenta significativamente a chance de o jovem estar na condição de nem-nem desocupado, assim como no caso do nem-nem inativo. Em 2004, a chance era $366 \%$ maior do que quando não havia outro nem-nem no domicílio. Em 2014, a chance se reduziu para $271 \%$, ou seja, ainda era extremamente elevada. Em 2015, ano do início da crise econômica, parou de cair, chegando a $290 \%$. Esses valores parecem demonstrar que a condição de nem-nem desocupado poderia estar associada às condições familiares e locais. Um nem-nem desocupado na família favorece a existência de outro nem-nem na mesma situação.

\subsubsection{Total de jovens nem-nem (inativos e desocupados)}

Um terceiro conjunto de resultados refere-se ao total de jovens nem-nem, que são apresentados nas Tabelas A7 a A9 do anexo para os anos de 2004, 2014 e 2015. Observa-se que a maioria dos coeficientes estimados é significativa, exceto para cor/raça em 2004, as faixas etárias, em 2014 e 2015, o fato de ter mãe viva e para as Regiões Sul e Sudeste em todos os anos.

Os resultados apresentados revelam uma combinação dos determinantes das condições de inatividade e de desocupação identificados nas duas seções anteriores.

Por sexo, em 2004, as mulheres tinham 19\% mais chances de ser nem-nem do que os homens. Ou seja, predomina o resultado encontrado para o subconjunto de nem-nem inativos onde a razão de chance das mulheres é mais elevada que a dos homens. Em 2014, essa chance havia aumentado para $27 \%$, recuando para $23 \%$ em 2015. Comparando esse resultado com o apresentado no gráfico 2, em que se observa que a taxa de jovens nem-nem das mulheres permanece muito mais elevada que a dos homens, a despeito do maior crescimento que ocorreu na taxa masculina no período em análise. Ou seja, ocorreu aumento da quantidade de homens jovens na condição nem-nem em relação ao total de homens jovens, entretanto, a despeito deste aumento, para a totalidade dos jovens a chance de estar nesta condição ainda é mais elevada para as mulheres jovens. 
Em relação à escolaridade, os jovens com ensino médio completo e ensino superior completo possuem maiores chances de ser nem-nem (inativos ou desocupados) do que os jovens com ensino fundamental incompleto. Houve redução nas chances nesses níveis de escolaridade entre 2004 e 2014, mas voltou a crescer em 2015. No ensino médio completo passou de $66 \%$ para $29 \%$ e, em seguida, para $50 \%$. No ensino superior completo passou de $54 \%$ para $29 \%$ e, em 2015, para $34 \%$. Essa redução entre os anos de 2004 e 2014 pode ser explicada, por um lado, devido ao melhor momento do mercado de trabalho nesse período que absorveu uma maior quantidade de jovens, privilegiando os mais escolarizados, o que reduziu as chances dos jovens com essas formações. Em 2015, as chances de ser nem-nem aumentaram em quase todos os níveis de escolaridade, provavelmente por conta das condições desfavoráveis da economia.

Por outro lado, associando esse resultado com a pequena chance de ser nem-nem caso já tenha trabalhado antes, uma possibilidade é que os jovens que se formam no ensino médio e no ensino superior, mas permanecem fora do mercado de trabalho, possuem maiores chances de ser nem-nem do que jovens menos escolarizados devido à opção de algumas mulheres pelos cuidados domiciliares e domésticos, pela falta de experiência profissional e pela falta de demanda por trabalho.

Por faixa etária, os jovens entre 15 e 17 anos possuem menores chances que os demais de serem nem-nem, até porque nessa faixa etária muitos ainda estão estudando. Contudo, os jovens entre 18 e 24 anos possuíam praticamente as mesmas chances que os jovens de 25 a 29 anos, em 2004. Em 2014 e 2015, os dados não são significantes.

O rendimento domiciliar apresenta uma forte influência para a condição nem-nem, pois quanto menor o nível de rendimento maior a chance do jovem ser nem-nem, assim como nos resultados apresentados para os subgrupos de inativos e de desocupados. As chances dos jovens dos domicílios mais pobres permaneceram acima de $300 \%$ em relação aos jovens dos domicílios mais ricos em todos os anos analisados.

Por condição na família, o cônjuge apresentou as maiores chances em relação à pessoa de referência nos anos analisados, contudo essas chances se reduziram. Em 2004, era de 179\%, em 2014, diminuiu a um terço, chegando a $66 \%$ e, em 2015, caiu para 58\%. Os demais membros (filhos e outros) do domicílio permaneceram com menores chances do que a pessoa de referência, provavelmente por incluir muitos jovens que ainda estão na escola. Essa redução das chances dos cônjuges pode estar associada à maior entrada de mulheres no mercado de trabalho. Normalmente, a mulher é considerada como cônjuge exceto nas famílias monoparentais chefiadas por mulheres.

Os resultados por Grande Região indicam que os jovens das regiões Norte e Nordeste teriam menos chances de ser nem-nem do que na Região Centro-Oeste, não tendo havido alterações nos anos analisados. Os resultados para as Regiões Sul e Sudeste não se mostraram significantes.

Assim como nos dois subgrupos dos jovens nem-nem, ter mãe viva, ter trabalhado antes e existir crianças no domicílio diminuem as chances do jovem ser nem-nem. Essas chances mudaram muito pouco entre 2004 e 2015.

Por sua vez, possuir filhos pequenos aumenta sensivelmente a chance de um jovem estar na condição nem-nem, o que faz bastante sentido por conta das dificuldades de se conseguir uma creche 
ou outra pessoa para cuidar das crianças. Ressaltando-se ainda que essas chances aumentaram entre 2004 e 2014, de $163 \%$ para 271\%. Em 2015, permaneceu elevada.

Outro fator que eleva a chance de o jovem ser nem-nem, é ter outro jovem nem-nem no domicílio. Nesse caso, como apontado anteriormente, parecem existir problemas localizados no acesso ao ensino e ao mercado de trabalho que levam os jovens a essa condição como oferta insuficiente de escola e de empregos, mas também podem ocorrer situações em que, principalmente, as mulheres jovens dos domicílios cuidam dos serviços domésticos e de familiares permanecendo fora da escola e do mercado de trabalho.

\subsubsection{Resumo dos principais resultados}

As mulheres têm mais chances de ser jovem nem-nem do que os homens, porém essa chance é maior dentro do subgrupo de jovens inativos e na sua totalidade, já que entre os jovens desocupados os homens apresentam maiores chances.

Por nível de escolaridade, os jovens com ensino médio e com ensino superior completo possuem mais chances de ser nem-nem do que os jovens com ensino fundamental incompleto. Contudo, isso ocorre de maneira mais expressiva dentro do subgrupo dos desocupados, já que entre os inativos o jovem com ensino fundamental incompleto possui maiores chances de estar nessa condição do que aqueles nos demais níveis de escolaridade.

Por faixa etária, os jovens de 15 a 17 anos de idade possuem as menores chances de ser nemnem, enquanto aqueles entre 18 e 24 anos possuem praticamente a mesma chance que os jovens entre 25 e 29 anos. Entretanto, entre os desocupados, os jovens de 18 a 24 anos possuem maiores chances que os jovens mais velhos, enquanto entre os inativos os de 25 a 29 anos prevalecem.

O nível de rendimento domiciliar contribui fortemente para a condição nem-nem. As chances são maiores e crescentes na medida em que se reduz o rendimento domiciliar per capita. Observa-se que os diferenciais entre as razões de chances no caso dos nem-nem desocupados são bem mais elevados do que entre os inativos. Isso mostra que a necessidade financeira dos mais pobres os obriga a ir em busca de um emprego, principalmente os homens, permanecendo desocupados.

Por condição na família, o jovem cônjuge tem mais chances de ser nem-nem. Entre os inativos, essa condição se confirma, pois normalmente os cônjuges são as mulheres. Mas entre os desocupados, os jovens que são as pessoas de referência na família têm mais chances que os cônjuges. Nesse último caso, em geral, a pessoa de referência é um homem.

Ter a mãe viva, a presença da mãe ou de crianças no domicílio assim como ter trabalhado anteriormente apresentaram resultados positivos para a condição nem-nem e para seus subgrupos, reduzindo as suas chances, enquanto a existência de outro jovem nem-nem atua negativamente, aumentado as chances de jovens estarem nessa condição.

Os dados regionais apresentaram problemas de significância, mas pode-se afirmar a partir dos resultados do modelo que os jovens das regiões Sul e Sudeste possuem mais chances de estarem na condição nem-nem desocupado do que nas demais regiões. 
Em resumo, diversos fatores contribuem na determinação do jovem estar na condição nemnem. Para os jovens inativos, a baixa escolaridade, a presença de filhos pequenos, o casamento, o baixo nível de rendimento domiciliar per capita e a falta de experiência profissional são os fatores que mais contribuem para a condição de nem-nem. As mulheres possuem mais chances do que os homens de estarem nessa situação.

Para os jovens desocupados, os fatores que se destacam são o baixo nível de rendimento domiciliar per capita, faixa etária entre 18 e 24 anos, possuir ensino médio completo ou superior completo, ser a pessoa de referência, possuir outro nem-nem no domicílio e pouca experiência profissional.

Conclui-se, portanto, que os jovens nem-nem possuem características e determinantes nitidamente distintos dentro dos subgrupos de inativos e de desocupados. Tal resultado fortalece a proposta deste estudo no sentido de separar os dois grupos e explorar suas diferenças.

\section{Conclusões}

Analisando a situação brasileira entre 2004 e 2015, os resultados apontam que a taxa média de jovens nem-nem inativos e desocupados de 15 a 29 anos apresentou um aumento de $19,7 \%$ para $22,5 \%$. Até 2014 a taxa permaneceu relativamente estável, apresentando um salto em 2015, quando a economia sofreu forte queda do PIB. Neste último ano, a taxa de nem-nem inativos atingia 14,4\%, enquanto a de nem-nem desocupados era de $8,1 \%$.

A taxa média, entretanto, esconde uma importante mudança na sua composição por sexo. A situação para as mulheres é bem mais desfavorável do que para os homens, apesar do aumento da taxa ter sido maior entre os homens entre 2004 e 2015. A taxa feminina que era quase o triplo da masculina em 2004 passou a ser o dobro em 2015, sendo de $29,8 \%$ para as mulheres e $15,4 \%$ para os homens.

Os estudos realizados anteriormente sobre os jovens nem-nem brasileiros focam basicamente na parcela de jovens inativos. Os jovens nem-nem inativos são predominantemente mulheres, com baixo nível de escolaridade, provenientes de domicílios pobres, cônjuges, na maioria dos casos com filhos pequenos, de cor parda ou negra. A participação de homens entre os nem-nem inativos tem aumentado, tema que merece um aprofundamento em novos estudos sobre os nem-nem no Brasil.

Em que pese a importância dos jovens inativos no conjunto dos jovens brasileiros na condição nem-nem, seria relevante a sua compreensão dentro de um contexto mais amplo e afinado com o conceito internacionalmente aceito. Ao se considerar que o jovem desocupado já fez uma opção pelo mercado de trabalho, apesar de não estar inserido ativamente nele, parte-se do pressuposto de que sua situação seria menos grave que a dos inativos, o que não necessariamente ocorre. Em alguns casos, a inatividade é uma opção, enquanto a desocupação demonstra uma situação de vulnerabilidade econômica e social. Ao considerar separadamente os nem-nem inativos dos desocupados, o artigo encontrou diferenças significativas entre os dois grupos, conforme destacado ao longo da seção 2.

A principal contribuição do estudo foi, sem dúvida, apresentar pela primeira vez os determinantes para o conjunto dos jovens nem-nem de acordo com o conceito internacionalmente aceito (desocupados e inativos), assim como a análise desagregada dos jovens nem-nem para cada 
um desses grupos. Dessa forma, foram identificadas duas situações com características diferenciadas que não são objeto de análise nos trabalhos anteriores realizados no país. As políticas públicas voltadas para um grupo não seriam as mesmas voltadas para o segundo.

A condição nem-nem mais desfavorável para as mulheres, a despeito da maior inserção das mulheres tanto no mercado de trabalho quanto no sistema educacional, que ocasionaram uma redução significativa da taxa de fecundidade, ainda relaciona-se à necessidade das mulheres ficarem sem estudar e/ou trabalhar para cuidar da família e dos afazeres domésticos no chamado trabalho reprodutivo. Essa maior carga das mulheres dificulta a sua entrada e a sua permanência no mercado de trabalho e na escola em um contexto de escassa oferta de creches públicas e privadas, distribuição desigual por sexo dos afazeres domésticos e cuidados de familiares e uma situação em que a presença de filhos ainda é um fator determinante para as jovens estarem nesta condição.

A evasão escolar precoce pode ocorrer também por necessidade econômica, dado que um dos principais determinantes para a condição nem-nem inativa e desocupada é a presença do jovem nos quintos de rendimento domiciliar inferiores. Mas é preciso garantir que esse jovem consiga acesso ao mercado de trabalho, pois os resultados apontam que o fato de ter trabalhado antes reduz significativamente as chances de o jovem estar nesta condição, principalmente entre os inativos.

Os resultados apresentados mostram que os grupos mais pobres e mais vulneráveis tiveram sua situação agravada pela crise econômica em 2015, pois como são jovens e com baixo nível de escolaridade e tendem a ser os primeiros a serem rejeitados pelo mercado de trabalho e os últimos a conseguirem recolocação.

Essa dificuldade latente nesse grupo de jovens mostra a necessidade da adoção de políticas públicas que possibilitem ao máximo a permanência dos jovens na escola através do auxílio econômico às famílias mais pobres, ampliação da geração de emprego e renda, assim como iniciativas voltadas à inserção de jovens com estímulos públicos para empresas e outras organizações.

Os resultados confirmam a vulnerabilidade social e econômica dos jovens nem-nem brasileiros no período em análise, pois estão mais presentes entre os mais pobres, com filhos, sem estrutura familiar e sem experiência no mercado de trabalho, necessitando de políticas públicas específicas para mitigar a sua condição.

Quanto à sugestão de trabalhos futuros sobre o tema, a inclusão do ano de 2015 permitiu a identificação de retrocesso na situação dos jovens nem-nem. Na medida em que a crise econômica se aprofundou em 2016 e a recuperação tem sido muito lenta, a expectativa é que tenha aumentado o estoque de nem-nem no país e piorado sua situação. Portanto, uma atualização do estudo para um período mais recente seria desejável oferecendo novas informações sobre esse importante tema. $\mathrm{O}$ ano de 2020 deveria merecer uma atenção especial por conta da crise da Covid-19, que fez um grande estrago no mercado de trabalho em geral, certamente trazendo reflexos para a população de nem-nem. Tal atualização poderia ser desenvolvida utilizando-se os dados da PNAD Contínua do IBGE disponibilizados a partir de 2012.

Sugere-se ainda uma análise regional mais desagregada do que por Grandes Regiões como a aqui realizada para diferenciar ainda mais os desníveis regionais do país e a situação dos nem-nem. 
Embora parte dos resultados regionais obtidos não tenha sido estatisticamente significativa, as diferenças encontradas entre as regiões mostram que há aí um potencial para novos estudos.

\section{Bibliografia}

BLINDER, S. Wage discrimination: reduced form and structural estimates. Journal of Human Resources, v. 8, n. 4, p. 436-455, 1973.

CABANAS, P.; KOMATSU, B. K.; MENEZES-FILHO, N. A. Crescimento da renda e as escolhas dos jovens entre os estudos e o mercado de trabalho. In: ENCONTRO NACIONAL DA ASSOCIAÇÃO NACIONAL DE PÓS-GRADUAÇÃO EM ECONOMIA, 2014.

CAMARANO, A. A.; KANSO, S. O que estão fazendo os jovens que não estudam, não trabalham e não procuram trabalho? Boletim do Mercado de trabalho. Conjuntura e Análise, Rio de Janeiro, IPEA, v. 53, 2012.

CAMARANO, A. A.; KANSO, S.; MELLO, J. L.; ANDRADE, A. Estão fazendo a transição os jovens que não estudam, não trabalham e não procuram trabalho? In: CAMARANO, A. A. (Org.). Transição para a vida adulta ou vida adulta em transição? Rio de Janeiro: Ipea, 2006.

CARDOSO, A. Juventude, trabalho e desenvolvimento: elementos para uma agenda de investigação. Caderno CRH, Salvador, v. 26, n. 68, ago. 2013.

CIRÍACO, J. da S.; MONTE, P. A. A situação ocupacional e educacional dos jovens no Brasil: 2002 a 2012. In: ENCONTRO NACIONAL DA ASSOCIAÇÃO BRASILEIRA DE ESTUDOS DO TRABALHO, 14, 2015. Disponível em: http://abet2015.com.br/wp-content/uploads/2015/09/Julianeda-Silva-Ciriaco.pdf.

COSTA, J. S.; ULYSSEA, G. O fenômeno dos jovens nem-nem. In: CORSEUIL, C. H.; BOTELHO, R. U. (Org.). Desafios à trajetória profissional dos jovens brasileiros. Rio de Janeiro: Ipea, 2014.

CUZZOCREA, V. Projecting the category NEET in the future. In: PERSPECTIVES on youth. What do you see? Council of Europe, Co E-EC Youth Partnership, 2014. p. 69-82.

DE HOYOS, R.; FIERROS, C. G.; VARGAS, J. V. Idle youth in Mexico trapped between the war on drugs and economic crisis. Education Global Practice Group. Policy Research, World Bank Group, 2016. (Working Paper, n. 7558).

DE HOYOS, R.; POPOVA, A.; ROGERS, H. Out of school and out of work a diagnostic of Ninis in Latin America. Policy Research, World Bank Group, 2016. (Working Paper, n. 7548).

DE HOYOS, R.; ROGERS, H.; SZÉKELY, M. Out of school and out of work: risk and opportunities for Latin America's Ninis. Washington, DC: World Bank, 2016. Disponível em: https://openknowledge.worldbank.org/handle/10986/22349.

DENNET, J.; SASSER MODESTINO, A. Uncertain futures? Youth attachment to the labor market in the United States and New England. New England Public Policy Center, Dec. 2013. (Research Report, n. 13-3).

FREIRE DA MOTA, D. G. Os jovens que nem trabalham e nem estudam no Brasil: Caracterização e transformações no período 2004/2015. Tese (Doutorado)-IE/PPGE/UFRJ, Rio de Janeiro, 2018. 
FRICKER, R. Logistic regression for survey data - Lecture16. Apresentação em slides. 2016.

FURLONG, A. The zone of precarity and discourses of vulnerability: NEET in the UK, Comparative Studies on NEET, Freeter, and Unemployed Youth in Japan and the UK)'. The Journal of Social Sciences and Humanities Education, v. 42, p. 101-121, 2007.

FURLONG, A. KELLY, P. The Brazilianisation of youth transitions in Australia and the UK. Australian Journal of Social Issues, v. 40, p. 207-255, 2005.

HOFFMANN, R. Como aposentadorias e pensões afetam a educação e o trabalho de jovens do domicílio. Economia e Sociedade, Campinas, v. 19, n. 1, p. 201-209, abr. 2010. Disponível em: http://www.scielo.br/pdf/ecos/v19n1/a08v19n1. Acesso em: 20 dez. 2021.

IBGE. INSTITUTO BRASILEIRO DE GEOGRAFIA E ESTATÍSTICA - Pesquisa Nacional por Amostra de Domicílios. Documentação dos microdados da amostra, Rio de Janeiro, 2015.

MARSHALL, K. Youth neither enrolled nor employed. Perspectives on Labour and Income, v. 24, n. 2, p. 1, 2012.

MONTEIRO, J. Quem são os jovens nem-nem? Uma análise sobre os jovens que não estudam e não participam do mercado de trabalho. FGV/IBRE, 2013. (Texto de Discussão, n. 34).

OLIVEIRA, M. M. de. Modelos de escolha binária. 1998. Disponível em: http://www.fep.up.pt/disciplinas/2E103/modelos de escolha binaria.pdf.

O’DEA, B.; GIOZIER, N.; PURCELL, R.; McCGORRY, P. D.; SCOTT, J.; FEILDS, K. L., HICKIE, I. B. A cross-sectional exploration of the clinical characteristics of disengaged (NEET) young people in primary mental healthcare. BMJ Open, v. 4, n. 12, e006378. 2014. Disponível em: http://dx.doi.org/10.1136/bmjopen-2014-006378.

OSE, S. O.; JENSEN, C. Youth outside the labour force - Perceived barriers by service providers and service users: a mixed method approach. Children and Youth Services Review, v. 81, p. 148-156, Oct. 2017. Disponível em: https://doi.org/10.1016/j.childyouth.2017.08.002.

OAXACA, R. Male-female wage differentials in urban labor markets. International Economic Review, p. 693-709, 1973.

QUINTINI, G.; MARTIN, J. P.; MARTINS S. The changing nature of the school-to-work transition process in OECD Countries. WDA-HSG, 2007. (Discussion Paper, n. 2007-2). Disponível em: http://dx.doi.org/10.2139/ssrn.1884070.

REIS, M. C.; CAMARGO, J. M. Impactos de aposentadorias e pensões sobre a educação e a participação dos jovens na força de trabalho. Pesquisa e Planejamento Econômico, v. 37. n. 2, ago 2016.

SERRACANT, P. Generación Ni-Ni. Estigmatització e exclusió social. Gènesi i evolició d'un concepte problemàtic e proposta d'un nou indicador. Barcelona: Observatori Català de la Joventut, 2012.

TILLMANN, E.; COMIM, F. Os determinantes da decisão entre estudo e trabalho e a geração nemnem. Pesquisa e Planejamento Econômico, v. 46. n. 2, ago. 2016. 


\section{Anexo}

Tabela A1

Resultados Modelo Logit para jovens nem-nem inativos - Brasil - 2004

\begin{tabular}{|c|c|c|c|c|c|}
\hline \multicolumn{2}{|c|}{ Coeficiente } & $\mathrm{B}$ & $|\mathrm{CV}(\beta)|$ & p-valor & $\exp (\beta)$ \\
\hline \multicolumn{2}{|c|}{ Intercepto } & $-0,99$ & 0,09 & 0,00 & 0,37 \\
\hline Sexo & $\begin{array}{l}\text { Homem } \\
\text { Mulher } \\
\end{array}$ & $\begin{array}{c}- \\
0,39 \\
\end{array}$ & $\begin{array}{c}- \\
0,03 \\
\end{array}$ & $\begin{array}{c}- \\
0,00 \\
\end{array}$ & $\begin{array}{c}- \\
1,47 \\
\end{array}$ \\
\hline Cor ou raça & \begin{tabular}{|l|} 
Branco \\
Não-branco \\
\end{tabular} & $\begin{array}{c}- \\
-0,05 \\
\end{array}$ & $\begin{array}{c}- \\
0,03 \\
\end{array}$ & $\begin{array}{c}- \\
0,13 \\
\end{array}$ & $\begin{array}{c}- \\
0,96 \\
\end{array}$ \\
\hline Nível de instrução & $\begin{array}{l}\text { Até EF incompleto } \\
\text { EF comp. } \\
\text { EM incompleto. } \\
\text { EM completo } \\
\text { ES incompleto } \\
\text { ES completo } \\
\end{array}$ & $\begin{array}{c}- \\
-0,61 \\
-1,39 \\
-0,28 \\
-2,45 \\
-0,23 \\
\end{array}$ & $\begin{array}{c}- \\
0,05 \\
0,05 \\
0,04 \\
0,13 \\
0,10 \\
\end{array}$ & $\begin{array}{c}- \\
0,00 \\
0,00 \\
0,00 \\
0,00 \\
0,03 \\
\end{array}$ & $\begin{array}{c}- \\
0,55 \\
0,25 \\
0,76 \\
0,09 \\
0,80\end{array}$ \\
\hline Faixa etária & $\begin{array}{l}15 \text { a } 17 \text { anos } \\
18 \text { a } 24 \text { anos } \\
25 \text { a } 29 \text { anos } \\
\end{array}$ & $\begin{array}{c}-1,21 \\
0,00 \\
- \\
\end{array}$ & $\begin{array}{c}0,05 \\
0,03 \\
- \\
\end{array}$ & $\begin{array}{c}0,00 \\
0,96 \\
- \\
\end{array}$ & $\begin{array}{r}0,30 \\
1,00 \\
- \\
\end{array}$ \\
\hline $\begin{array}{l}\text { Quintos de rendimento domiciliar } \\
\text { per capita (em salário-mínimo) }\end{array}$ & $\begin{array}{l}1^{\circ} \text { quinto } \\
2^{\circ} \text { quinto } \\
3^{\circ} \text { quinto } \\
4^{o} \text { quinto } \\
5^{\circ} \text { quinto }\end{array}$ & $\begin{array}{c}0,64 \\
0,54 \\
0,47 \\
0,21 \\
- \\
\end{array}$ & $\begin{array}{c}0,06 \\
0,05 \\
0,05 \\
0,05 \\
- \\
\end{array}$ & $\begin{array}{l}0,00 \\
0,00 \\
0,00 \\
0,00 \\
- \\
\end{array}$ & $\begin{array}{c}1,89 \\
1,71 \\
1,60 \\
1,24 \\
- \\
\end{array}$ \\
\hline Condição no domicílio & $\begin{array}{l}\text { Referência } \\
\text { Cônjuge } \\
\text { Filho } \\
\text { Outro parente / agregado } \\
\text { Não parente } \\
\end{array}$ & $\begin{array}{c}- \\
1,23 \\
-0,21 \\
-0,22 \\
-1,11 \\
\end{array}$ & $\begin{array}{c}- \\
0,05 \\
0,05 \\
0,07 \\
0,41 \\
\end{array}$ & $\begin{array}{c}- \\
0,00 \\
0,00 \\
0,00 \\
0,01 \\
\end{array}$ & $\begin{array}{c}- \\
3,41 \\
0,81 \\
0,80 \\
0,33 \\
\end{array}$ \\
\hline Grande Região & $\begin{array}{l}\text { Norte } \\
\text { Nordeste } \\
\text { Sudeste } \\
\text { Sul } \\
\text { Centro-Oeste } \\
\end{array}$ & $\begin{array}{c}-0,08 \\
-0,23 \\
-0,13 \\
0,08 \\
- \\
\end{array}$ & $\begin{array}{c}0,05 \\
0,05 \\
0,05 \\
0,06 \\
- \\
\end{array}$ & $\begin{array}{c}0,15 \\
0,00 \\
0,00 \\
0,15 \\
- \\
\end{array}$ & $\begin{array}{c}0,93 \\
0,80 \\
0,87 \\
1,09 \\
- \\
\end{array}$ \\
\hline Tem mãe viva & Sim & $-0,13$ & 0,05 & 0,02 & 0,88 \\
\hline Mãe mora no domicílio & Sim & $-0,26$ & 0,05 & 0,00 & 0,77 \\
\hline Filhos de até 5 anos & Sim & 0,79 & 0,05 & 0,00 & 2,21 \\
\hline Já trabalhou antes & Sim & $-2,90$ & 0,04 & 0,00 & 0,06 \\
\hline Nem-nem no domicílio & Sim & 1,44 & 0,03 & 0,00 & 4,21 \\
\hline Crianças no domicílio & $\begin{array}{l}0 \\
1 \\
2 \\
3 \text { ou mais } \\
\end{array}$ & $\begin{array}{c}- \\
-0,10 \\
-0,13 \\
-0,12 \\
\end{array}$ & $\begin{array}{c}- \\
0,04 \\
0,06 \\
0,08 \\
\end{array}$ & $\begin{array}{c}- \\
0,02 \\
0,02 \\
0,16 \\
\end{array}$ & $\begin{array}{c}- \\
0,91 \\
0,88 \\
0,89 \\
\end{array}$ \\
\hline
\end{tabular}

Nota: $\beta$ é o estimador e CV ( $\beta$ ) representa o coeficiente de variação do estimador.

Fonte: Elaboração dos autores a partir da Pesquisa Nacional por Amostra de Domicílios (2004). 
Determinantes para a condição nem-nem dos jovens brasileiros: uma análise desagregada de inativos e desocupados

Tabela A2

Resultados Modelo Logit para jovens nem-nem inativos - Brasil - 2014

\begin{tabular}{|c|c|c|c|c|c|}
\hline \multicolumn{2}{|c|}{ Coeficiente } & $\beta$ & $|\mathrm{CV}(\beta)|$ & p-valor & $\exp (\beta)$ \\
\hline \multicolumn{2}{|c|}{ Intercepto } & $-0,43$ & 0,11 & 0,00 & 0,65 \\
\hline \multirow{2}{*}{ Sexo } & Homem & - & - & - & - \\
\hline & Mulher & 0,33 & 0,04 & 0,00 & 1,39 \\
\hline \multirow{2}{*}{ Cor ou raça } & Branco & - & - & - & - \\
\hline & Não-branco & $-0,01$ & 0,03 & 0,67 & 0,99 \\
\hline \multirow{6}{*}{ Nível de instrução } & Até EF incompleto & - & - & - & - \\
\hline & EF comp. & $-0,57$ & 0,05 & 0,00 & 0,56 \\
\hline & EM incompleto & $-1,21$ & 0,05 & 0,00 & 0,30 \\
\hline & EM completo & $-0,22$ & 0,04 & 0,00 & 0,80 \\
\hline & ES incompleto & $-2,53$ & 0,09 & 0,00 & 0,08 \\
\hline & ES completo & $-0,58$ & 0,08 & 0,00 & 0,56 \\
\hline \multirow{3}{*}{ Faixa etária } & 15 a 17 anos & $-1,63$ & 0,05 & 0,00 & 0,20 \\
\hline & 18 a 24 anos & $-0,09$ & 0,04 & 0,02 & 0,92 \\
\hline & 25 a 29 anos & - & - & - & - \\
\hline \multirow{5}{*}{$\begin{array}{l}\text { Quintos de rendimento domiciliar } \\
\text { per capita } \\
\text { (em salário-mínimo) }\end{array}$} & $1^{\circ}$ quinto & 0,60 & 0,06 & 0,00 & 1,82 \\
\hline & $2^{\circ}$ quinto & 0,62 & 0,06 & 0,00 & 1,86 \\
\hline & $3^{\circ}$ quinto & 0,43 & 0,06 & 0,00 & 1,54 \\
\hline & $4^{\circ}$ quinto & 0,22 & 0,06 & 0,00 & 1,25 \\
\hline & $5^{\circ}$ quinto & - & - & - & - \\
\hline \multirow{5}{*}{ Condição no domicílio } & Referência & - & - & - & - \\
\hline & Cônjuge & 0,69 & 0,05 & 0,00 & 2,00 \\
\hline & Filho & $-0,23$ & 0,06 & 0,00 & 0,79 \\
\hline & Outro parente / agregado & $-0,45$ & 0,07 & 0,00 & 0,64 \\
\hline & Não parente & $-1,62$ & 0,59 & 0,01 & 0,20 \\
\hline \multirow{5}{*}{ Grande Região } & Norte & $-0,29$ & 0,06 & 0,00 & 0,75 \\
\hline & Nordeste & $-0,20$ & 0,05 & 0,00 & 0,82 \\
\hline & Sudeste & $-0,13$ & 0,05 & 0,01 & 0,88 \\
\hline & Sul & 0,02 & 0,06 & 0,80 & 1,02 \\
\hline & Centro-Oeste & - & - & - & - \\
\hline Tem mãe viva & Sim & 0,00 & 0,07 & 0,98 & 1,00 \\
\hline Mãe mora no domicílio & Sim & $-0,39$ & 0,05 & 0,00 & 0,68 \\
\hline Filhos de até 5 anos & Sim & 1,22 & 0,06 & 0,00 & 3,40 \\
\hline Já trabalhou antes & Sim & $-3,06$ & 0,04 & 0,00 & 0,05 \\
\hline Nem-nem no domicílio & Sim & 1,40 & 0,04 & 0,00 & 4,07 \\
\hline \multirow{4}{*}{ Crianças no domicílio } & 0 & - & - & - & - \\
\hline & 1 & $-0,24$ & 0,05 & 0,00 & 0,78 \\
\hline & 2 & $-0,13$ & 0,07 & 0,06 & 0,88 \\
\hline & 3 ou mais & $-0,02$ & 0,14 & 0,87 & 0,98 \\
\hline
\end{tabular}

Nota: $\beta$ é o estimador e CV $(\beta)$ representa o coeficiente de variação do estimador.

Fonte: Elaboração dos autores a partir da Pesquisa Nacional por Amostra de Domicílios (2014). 
Tabela A3

Resultados Modelo Logit para jovens nem-nem inativos - Brasil - 2015

\begin{tabular}{|c|c|c|c|c|c|}
\hline \multicolumn{2}{|c|}{ Coeficiente } & $\beta$ & $|\mathrm{CV}(\beta)|$ & p-valor & $\exp (\beta)$ \\
\hline \multicolumn{2}{|c|}{ Intercepto } & $-0,30$ & 0,11 & 0,01 & 0,74 \\
\hline Sexo & $\begin{array}{l}\text { Homem } \\
\text { Mulher }\end{array}$ & $\begin{array}{c}- \\
0,40 \\
\end{array}$ & $\begin{array}{c}- \\
0,03\end{array}$ & $\begin{array}{c}- \\
0,00\end{array}$ & $\begin{array}{c}- \\
1,49\end{array}$ \\
\hline Cor ou raça & \begin{tabular}{|l|} 
Branco \\
Não-branco \\
\end{tabular} & $\begin{array}{c}- \\
-0,03 \\
\end{array}$ & $\begin{array}{c}- \\
0,03 \\
\end{array}$ & $\begin{array}{c}- \\
0,30 \\
\end{array}$ & $\begin{array}{c}- \\
0,97 \\
\end{array}$ \\
\hline Nível de instrução & $\begin{array}{l}\text { Até EF incompleto } \\
\text { EF comp. } \\
\text { EM incompleto } \\
\text { EM completo } \\
\text { ES incompleto } \\
\text { ES completo }\end{array}$ & $\begin{array}{c} \\
-0,54 \\
-1,22 \\
-0,31 \\
-2,62 \\
-0,73\end{array}$ & $\begin{array}{c}- \\
0,05 \\
0,05 \\
0,04 \\
0,09 \\
0,08\end{array}$ & $\begin{array}{c}- \\
0,00 \\
0,00 \\
0,00 \\
0,00 \\
0,00\end{array}$ & $\begin{array}{c}- \\
0,58 \\
0,30 \\
0,74 \\
0,07 \\
0,48 \\
\end{array}$ \\
\hline Faixa etária & $\begin{array}{l}15 \text { a } 17 \text { anos } \\
18 \text { a } 24 \text { anos } \\
25 \text { a } 29 \text { anos }\end{array}$ & $\begin{array}{c}-1,69 \\
-0,09 \\
- \\
\end{array}$ & $\begin{array}{c}0,06 \\
0,03 \\
-\end{array}$ & $\begin{array}{c}0,00 \\
0,01 \\
-\end{array}$ & $\begin{array}{c}0,18 \\
0,92 \\
- \\
\end{array}$ \\
\hline $\begin{array}{l}\text { Quintos de rendimento domiciliar } \\
\text { per capita } \\
\text { (em salário-mínimo) }\end{array}$ & $\begin{array}{l}1^{\circ} \text { quinto } \\
2^{\circ} \text { quinto } \\
3^{\circ} \text { quinto } \\
4^{\circ} \text { quinto } \\
5^{\circ} \text { quinto } \\
\end{array}$ & $\begin{array}{c}0,51 \\
0,43 \\
0,33 \\
0,09 \\
- \\
\end{array}$ & $\begin{array}{c}0,06 \\
0,06 \\
0,06 \\
0,06 \\
- \\
\end{array}$ & $\begin{array}{l}0,00 \\
0,00 \\
0,00 \\
0,15 \\
- \\
\end{array}$ & $\begin{array}{c}1,67 \\
1,54 \\
1,39 \\
1,09 \\
- \\
\end{array}$ \\
\hline Condição no domicílio & $\begin{array}{l}\text { Referência } \\
\text { Cônjuge } \\
\text { Filho } \\
\text { Outro parente / agregado } \\
\text { Não parente } \\
\end{array}$ & $\begin{array}{c}- \\
0,63 \\
-0,18 \\
-0,46 \\
-0,91 \\
\end{array}$ & $\begin{array}{c}- \\
0,05 \\
0,06 \\
0,07 \\
0,49 \\
\end{array}$ & $\begin{array}{c}- \\
0,00 \\
0,00 \\
0,00 \\
0,06 \\
\end{array}$ & $\begin{array}{c}- \\
1,88 \\
0,83 \\
0,63 \\
0,40 \\
\end{array}$ \\
\hline Grande Região & $\begin{array}{l}\text { Norte } \\
\text { Nordeste } \\
\text { Sudeste } \\
\text { Sul } \\
\text { Centro-Oeste } \\
\end{array}$ & $\begin{array}{c}-0,20 \\
-0,14 \\
-0,26 \\
-0,12 \\
- \\
\end{array}$ & $\begin{array}{c}0,06 \\
0,05 \\
0,06 \\
0,06 \\
-\end{array}$ & $\begin{array}{c}0,00 \\
0,01 \\
0,00 \\
0,07 \\
- \\
\end{array}$ & $\begin{array}{c}0,82 \\
0,87 \\
0,77 \\
0,89 \\
- \\
\end{array}$ \\
\hline Tem mãe viva & Sim & $-0,06$ & 0,06 & 0,38 & 0,95 \\
\hline Mãe mora no domicílio & Sim & $-0,36$ & 0,05 & 0,00 & 0,70 \\
\hline Filhos de até 5 anos & Sim & 1,15 & 0,05 & 0,00 & 3,15 \\
\hline Já trabalhou antes & Sim & $-2,91$ & 0,04 & 0,00 & 0,05 \\
\hline Nem-nem no domicílio & Sim & 1,28 & 0,03 & 0,00 & 3,61 \\
\hline Crianças no domicílio & $\begin{array}{l}0 \\
1 \\
2 \\
3 \text { ou mais } \\
\end{array}$ & $\begin{array}{c}- \\
-0,25 \\
-0,23 \\
-0,04\end{array}$ & $\begin{array}{c}- \\
0,04 \\
0,07 \\
0,13 \\
\end{array}$ & $\begin{array}{c}- \\
0,00 \\
0,00 \\
0,74 \\
\end{array}$ & $\begin{array}{c}- \\
0,78 \\
0,80 \\
0,96\end{array}$ \\
\hline
\end{tabular}

Nota: $\beta$ é o estimador e CV ( $\beta$ ) representa o coeficiente de variação do estimador.

Fonte: Elaboração dos autores a partir da Pesquisa Nacional por Amostra de Domicílios (2015). 
Determinantes para a condição nem-nem dos jovens brasileiros: uma análise desagregada de inativos e desocupados

Tabela A4

Resultados Modelo Logit para jovens nem-nem desocupados - Brasil - 2004

\begin{tabular}{|c|c|c|c|c|c|}
\hline \multicolumn{2}{|c|}{ Coeficiente } & B & $|\mathrm{CV}(\beta)|$ & $\mathrm{p}$-valor & $\exp (\beta)$ \\
\hline \multicolumn{2}{|c|}{ Intercepto } & $-3,45$ & 0,11 & 0,00 & 0,03 \\
\hline Sexo & $\begin{array}{l}\text { Homem } \\
\text { Mulher }\end{array}$ & $\begin{array}{c}- \\
-0,11 \\
\end{array}$ & $\begin{array}{c}- \\
0,04\end{array}$ & $\begin{array}{c}- \\
0,01\end{array}$ & $\begin{array}{c}- \\
0,90\end{array}$ \\
\hline Cor ou raça & $\begin{array}{l}\text { Branco } \\
\text { Não-branco }\end{array}$ & $\begin{array}{c}- \\
0,13 \\
\end{array}$ & $\begin{array}{c}- \\
0,04 \\
\end{array}$ & $\begin{array}{c}- \\
0,00\end{array}$ & $\begin{array}{c}- \\
1,14 \\
\end{array}$ \\
\hline Nível de instrução & $\begin{array}{l}\text { Até EF incompleto } \\
\text { EF comp. } \\
\text { EM incompleto } \\
\text { EM completo } \\
\text { ES incompleto } \\
\text { ES completo }\end{array}$ & $\begin{array}{c}- \\
0,24 \\
-0,32 \\
1,05 \\
-0,84 \\
0,95\end{array}$ & $\begin{array}{c}- \\
0,05 \\
0,06 \\
0,04 \\
0,14 \\
0,11\end{array}$ & $\begin{array}{c}- \\
0,00 \\
0,00 \\
0,00 \\
0,00 \\
0,00\end{array}$ & $\begin{array}{c}- \\
1,27 \\
0,73 \\
2,87 \\
0,43 \\
2,59\end{array}$ \\
\hline Faixa etária & $\begin{array}{l}15 \text { a } 17 \text { anos } \\
18 \text { a } 24 \text { anos } \\
25 \text { a } 29 \text { anos }\end{array}$ & $\begin{array}{c}-1,42 \\
0,13 \\
- \\
\end{array}$ & $\begin{array}{c}0,07 \\
0,04 \\
-\end{array}$ & $\begin{array}{c}0,00 \\
0,00 \\
-\end{array}$ & $\begin{array}{c}0,24 \\
1,14 \\
- \\
\end{array}$ \\
\hline $\begin{array}{l}\text { Quintos de rendimento domiciliar } \\
\text { per capita (em salário-mínimo) }\end{array}$ & $\begin{array}{l}1^{\circ} \text { quinto } \\
2^{\circ} \text { quinto } \\
3^{\circ} \text { quinto } \\
4^{\circ} \text { quinto } \\
5^{\circ} \text { quinto }\end{array}$ & $\begin{array}{c}1,47 \\
1,16 \\
0,93 \\
0,59 \\
-\end{array}$ & $\begin{array}{c}0,07 \\
0,07 \\
0,07 \\
0,07 \\
- \\
\end{array}$ & $\begin{array}{c}0,00 \\
0,00 \\
0,00 \\
0,00 \\
- \\
\end{array}$ & $\begin{array}{c}4,35 \\
3,18 \\
2,54 \\
1,81 \\
-\end{array}$ \\
\hline Condição no domicílio & $\begin{array}{l}\text { Referência } \\
\text { Cônjuge } \\
\text { Filho } \\
\text { Outro parente / agregado } \\
\text { Não parente } \\
\end{array}$ & $\begin{array}{c}- \\
0,02 \\
-0,13 \\
-0,01 \\
-0,69 \\
\end{array}$ & $\begin{array}{c}- \\
0,06 \\
0,06 \\
0,08 \\
0,36\end{array}$ & $\begin{array}{c}- \\
0,72 \\
0,04 \\
0,88 \\
0,06\end{array}$ & $\begin{array}{c}- \\
1,02 \\
0,88 \\
0,99 \\
0,50\end{array}$ \\
\hline Grande Região & $\begin{array}{l}\text { Norte } \\
\text { Nordeste } \\
\text { Sudeste } \\
\text { Sul } \\
\text { Centro-Oeste } \\
\end{array}$ & $\begin{array}{c}-0,57 \\
-0,42 \\
0,18 \\
0,00 \\
- \\
\end{array}$ & $\begin{array}{c}0,07 \\
0,06 \\
0,05 \\
0,07 \\
- \\
\end{array}$ & $\begin{array}{c}0,00 \\
0,00 \\
0,00 \\
0,99 \\
- \\
\end{array}$ & $\begin{array}{c}0,56 \\
0,66 \\
1,19 \\
1,00 \\
-\end{array}$ \\
\hline Tem mãe viva & Sim & 0,07 & 0,07 & 0,33 & 1,07 \\
\hline Mãe mora no domicílio & Sim & $-0,21$ & 0,06 & 0,00 & 0,81 \\
\hline Filhos de até 5 anos & Sim & 0,31 & 0,06 & 0,00 & 1,36 \\
\hline Já trabalhou antes & Sim & $-1,26$ & 0,04 & 0,00 & 0,28 \\
\hline Nem-nem no domicílio & Sim & 1,54 & 0,04 & 0,00 & 4,66 \\
\hline Crianças no domicílio & $\begin{array}{l}0 \\
1 \\
2 \\
3 \text { ou mais }\end{array}$ & $\begin{array}{c}- \\
-0,26 \\
-0,30 \\
-0,41 \\
\end{array}$ & $\begin{array}{c}- \\
0,05 \\
0,06 \\
0,11 \\
\end{array}$ & $\begin{array}{c}- \\
0,00 \\
0,00 \\
0,00 \\
\end{array}$ & $\begin{array}{c}- \\
0,77 \\
0,74 \\
0,67\end{array}$ \\
\hline
\end{tabular}

Nota: $\beta$ é o estimador e CV $(\beta)$ representa o coeficiente de variação do estimador.

Fonte: Elaboração dos autores a partir da Pesquisa Nacional por Amostra de Domicílios (2004). 
Tabela A5

Resultados Modelo Logit para jovens nem-nem desocupados - Brasil - 2014

\begin{tabular}{|c|c|c|c|c|c|}
\hline \multicolumn{2}{|c|}{ Coeficiente } & $\beta$ & $|\mathrm{CV}(\beta)|$ & $\mathrm{p}$-valor & $\exp (\beta)$ \\
\hline \multicolumn{2}{|c|}{ Intercepto } & $-3,75$ & 0,14 & 0,00 & 0,02 \\
\hline \multirow{2}{*}{ Sexo } & Homem & - & - & - & - \\
\hline & Mulher & 0,00 & 0,04 & 0,99 & 1,00 \\
\hline \multirow{2}{*}{ Cor ou raça } & Branco & - & - & - & - \\
\hline & Não-branco & 0,12 & 0,04 & 0,00 & 1,13 \\
\hline \multirow{6}{*}{ Nível de instrução } & Até EF incompleto & - & - & - & - \\
\hline & EF comp. & 0,08 & 0,06 & 0,21 & 1,08 \\
\hline & EM incompleto & $-0,11$ & 0,06 & 0,06 & 0,89 \\
\hline & EM completo & 0,71 & 0,05 & 0,00 & 2,04 \\
\hline & ES incompleto & $-0,95$ & 0,12 & 0,00 & 0,39 \\
\hline & ES completo & 1,16 & 0,09 & 0,00 & 3,18 \\
\hline \multirow{3}{*}{ Faixa etária } & 15 a 17 anos & $-1,52$ & 0,08 & 0,00 & 0,22 \\
\hline & 18 a 24 anos & 0,18 & 0,04 & 0,00 & 1,19 \\
\hline & 25 a 29 anos & - & - & - & - \\
\hline \multirow{5}{*}{$\begin{array}{l}\text { Quintos de rendimento domiciliar } \\
\text { per capita (em salário-mínimo) }\end{array}$} & $1^{\circ}$ quinto & 1,69 & 0,09 & 0,00 & 5,40 \\
\hline & $2^{\circ}$ quinto & 1,37 & 0,08 & 0,00 & 3,94 \\
\hline & $3^{\circ}$ quinto & 0,89 & 0,08 & 0,00 & 2,44 \\
\hline & $4^{\circ}$ quinto & 0,50 & 0,08 & 0,00 & 1,65 \\
\hline & $5^{\circ}$ quinto & - & - & - & - \\
\hline \multirow{5}{*}{ Condição no domicílio } & Referência & - & - & - & - \\
\hline & Cônjuge & $-0,13$ & 0,06 & 0,03 & 0,88 \\
\hline & Filho & $-0,14$ & 0,07 & 0,04 & 0,87 \\
\hline & Outro parente / agregado & $-0,23$ & 0,08 & 0,00 & 0,79 \\
\hline & Não parente & 0,01 & 0,46 & 0,99 & 1,01 \\
\hline \multirow{5}{*}{ Grande Região } & Norte & $-0,23$ & 0,08 & 0,00 & 0,79 \\
\hline & Nordeste & $-0,13$ & 0,07 & 0,06 & 0,88 \\
\hline & Sudeste & 0,34 & 0,07 & 0,00 & 1,41 \\
\hline & Sul & 0,12 & 0,09 & 0,15 & 1,13 \\
\hline & Centro-Oeste & - & - & - & - \\
\hline Tem mãe viva & Sim & $-0,05$ & 0,08 & 0,56 & 0,95 \\
\hline Mãe mora no domicílio & Sim & $-0,10$ & 0,06 & 0,10 & 0,90 \\
\hline Filhos de até 5 anos & Sim & 0,22 & 0,07 & 0,00 & 1,25 \\
\hline Já trabalhou antes & Sim & $-1,01$ & 0,04 & 0,00 & 0,36 \\
\hline Nem-nem no domicílio & Sim & 1,36 & 0,04 & 0,00 & 3,90 \\
\hline \multirow{4}{*}{ Crianças no domicílio } & 0 & - & - & - & - \\
\hline & 1 & $-0,31$ & 0,05 & 0,00 & 0,73 \\
\hline & 2 & $-0,52$ & 0,09 & 0,00 & 0,60 \\
\hline & 3 ou mais & $-0,85$ & 0,17 & 0,00 & 0,43 \\
\hline
\end{tabular}

Nota: $\beta$ é o estimador e CV $(\beta)$ representa o coeficiente de variação do estimador.

Fonte: Elaboração dos autores a partir da Pesquisa Nacional por Amostra de Domicílios (2014). 
Determinantes para a condição nem-nem dos jovens brasileiros: uma análise desagregada de inativos e desocupados

Tabela A6

Resultados Modelo Logit para jovens nem-nem desocupados - Brasil - 2015

\begin{tabular}{|c|c|c|c|c|c|}
\hline \multicolumn{2}{|c|}{ Coeficiente } & $\beta$ & $|\mathrm{CV}(\beta)|$ & p-valor & $\exp (\beta)$ \\
\hline \multicolumn{2}{|c|}{ Intercepto } & $-3,58$ & 0,13 & 0,00 & 0,03 \\
\hline Sexo & $\begin{array}{l}\text { Homem } \\
\text { Mulher }\end{array}$ & $\begin{array}{c}- \\
-0,11 \\
\end{array}$ & $\begin{array}{c}- \\
0,04\end{array}$ & $\begin{array}{c}- \\
0,00\end{array}$ & $\begin{array}{c}- \\
0,89 \\
\end{array}$ \\
\hline Cor ou raça & $\begin{array}{l}\text { Branco } \\
\text { Não-branco }\end{array}$ & $\begin{array}{c}- \\
0,11 \\
\end{array}$ & $\begin{array}{c}- \\
0,04\end{array}$ & $\begin{array}{c}- \\
0,00\end{array}$ & $\begin{array}{c}- \\
1,12 \\
\end{array}$ \\
\hline Nível de instrução & $\begin{array}{l}\text { Até EF incompleto } \\
\text { EF comp. } \\
\text { EM incompleto } \\
\text { EM completo } \\
\text { ES incompleto } \\
\text { ES completo }\end{array}$ & $\begin{array}{c}- \\
0,26 \\
-0,10 \\
0,88 \\
-0,99 \\
1,21 \\
\end{array}$ & $\begin{array}{c}- \\
0,06 \\
0,07 \\
0,05 \\
0,11 \\
0,08\end{array}$ & $\begin{array}{c}- \\
0,00 \\
0,13 \\
0,00 \\
0,00 \\
0,00 \\
\end{array}$ & $\begin{array}{c}- \\
1,29 \\
0,91 \\
2,41 \\
0,37 \\
3,37 \\
\end{array}$ \\
\hline Faixa etária & $\begin{array}{l}15 \text { a } 17 \text { anos } \\
18 \text { a } 24 \text { anos } \\
25 \text { a } 29 \text { anos }\end{array}$ & $\begin{array}{c}-1,78 \\
0,14 \\
- \\
\end{array}$ & $\begin{array}{c}0,08 \\
0,04 \\
-\end{array}$ & $\begin{array}{c}0,00 \\
0,00 \\
-\end{array}$ & $\begin{array}{c}0,17 \\
1,15 \\
-\end{array}$ \\
\hline $\begin{array}{l}\text { Quintos de rendimento domiciliar per } \\
\text { capita (em salário-mínimo) }\end{array}$ & $\begin{array}{l}1^{\circ} \text { quinto } \\
2^{\circ} \text { quinto } \\
3^{\circ} \text { quinto } \\
4^{\circ} \text { quinto } \\
5^{\circ} \text { quinto }\end{array}$ & $\begin{array}{c}1,74 \\
1,46 \\
1,19 \\
0,57 \\
- \\
\end{array}$ & $\begin{array}{c}0,08 \\
0,08 \\
0,08 \\
0,08 \\
- \\
\end{array}$ & $\begin{array}{c}0,00 \\
0,00 \\
0,00 \\
0,00 \\
- \\
\end{array}$ & $\begin{array}{c}5,67 \\
4,31 \\
3,29 \\
1,77 \\
- \\
\end{array}$ \\
\hline Condição no domicílio & $\begin{array}{l}\text { Referência } \\
\text { Cônjuge } \\
\text { Filho } \\
\text { Outro parente / agregado } \\
\text { Não parente } \\
\end{array}$ & $\begin{array}{c}- \\
-0,10 \\
-0,16 \\
-0,32 \\
-0,42 \\
\end{array}$ & $\begin{array}{c}- \\
0,06 \\
0,06 \\
0,07 \\
0,38\end{array}$ & $\begin{array}{c}- \\
0,07 \\
0,01 \\
0,00 \\
0,27 \\
\end{array}$ & $\begin{array}{c}- \\
0,90 \\
0,85 \\
0,73 \\
0,65 \\
\end{array}$ \\
\hline Grande Região & $\begin{array}{l}\text { Norte } \\
\text { Nordeste } \\
\text { Sudeste } \\
\text { Sul } \\
\text { Centro-Oeste } \\
\end{array}$ & $\begin{array}{c}-0,49 \\
-0,30 \\
0,29 \\
0,17 \\
- \\
\end{array}$ & $\begin{array}{c}0,07 \\
0,07 \\
0,06 \\
0,07 \\
- \\
\end{array}$ & $\begin{array}{c}0,00 \\
0,00 \\
0,00 \\
0,02 \\
-\end{array}$ & $\begin{array}{c}0,61 \\
0,74 \\
1,34 \\
1,18 \\
- \\
\end{array}$ \\
\hline Tem mãe viva & Sim & 0,08 & 0,08 & 0,33 & 1,08 \\
\hline Mãe mora no domicílio & Sim & $-0,12$ & 0,06 & 0,04 & 0,89 \\
\hline Filhos de até 5 anos & Sim & 0,04 & 0,06 & 0,54 & 1,04 \\
\hline Já trabalhou antes & Sim & $-1,04$ & 0,04 & 0,00 & 0,35 \\
\hline Nem-nem no domicílio & Sim & 1,31 & 0,04 & 0,00 & 3,71 \\
\hline Crianças no domicílio & $\begin{array}{l}0 \\
1 \\
2 \\
3 \text { ou mais }\end{array}$ & $\begin{array}{c}- \\
-0,24 \\
-0,35 \\
-0,35\end{array}$ & $\begin{array}{c}- \\
0,05 \\
0,08 \\
0,15\end{array}$ & $\begin{array}{c}- \\
0,00 \\
0,00 \\
0,02\end{array}$ & $\begin{array}{c}- \\
0,78 \\
0,70 \\
0,70 \\
\end{array}$ \\
\hline
\end{tabular}

Nota: $\beta$ é o estimador e CV $(\beta)$ representa o coeficiente de variação do estimador.

Fonte: Elaboração dos autores a partir da Pesquisa Nacional por Amostra de Domicílios (2015). 
Tabela A7

Resultados Modelo Logit para o total de jovens nem-nem - Brasil - 2004

\begin{tabular}{|c|c|c|c|c|c|}
\hline \multicolumn{2}{|c|}{ Coeficiente } & $\beta$ & $|\mathrm{CV}(\beta)|$ & p-valor & $\exp (\beta)$ \\
\hline \multicolumn{2}{|c|}{ Intercepto } & $-0,70$ & 0,08 & 0,00 & 0,50 \\
\hline \multirow{2}{*}{ Sexo } & Homem & - & - & - & - \\
\hline & Mulher & 0,17 & 0,03 & 0,00 & 1,19 \\
\hline \multirow{2}{*}{ Cor ou raça } & Branco & - & - & - & - \\
\hline & Não-branco & 0,04 & 0,03 & 0,09 & 1,04 \\
\hline \multirow{6}{*}{ Nível de instrução } & Até EF incompleto & - & - & - & - \\
\hline & EF comp. & $-0,40$ & 0,04 & 0,00 & 0,67 \\
\hline & EM incompleto & $-1,41$ & 0,05 & 0,00 & 0,24 \\
\hline & EM completo & 0,51 & 0,03 & 0,00 & 1,66 \\
\hline & ES incompleto & $-2,29$ & 0,11 & 0,00 & 0,10 \\
\hline & ES completo & 0,43 & 0,08 & 0,00 & 1,54 \\
\hline \multirow{3}{*}{ Faixa etária } & 15 a 17 anos & $-1,81$ & 0,05 & 0,00 & 0,16 \\
\hline & 18 a 24 anos & 0,09 & 0,03 & 0,00 & 1,09 \\
\hline & 25 a 29 anos & - & - & - & - \\
\hline \multirow{5}{*}{$\begin{array}{l}\text { Quintos de rendimento } \\
\text { domiciliar per capita (em } \\
\text { salário-mínimo) }\end{array}$} & $1^{\circ}$ quinto & 1,47 & 0,05 & 0,00 & 4,35 \\
\hline & $2^{\circ}$ quinto & 1,17 & 0,05 & 0,00 & 3,21 \\
\hline & $3^{\circ}$ quinto & 0,97 & 0,05 & 0,00 & 2,63 \\
\hline & $4^{\circ}$ quinto & 0,56 & 0,05 & 0,00 & 1,74 \\
\hline & $5^{\circ}$ quinto & - & - & - & - \\
\hline \multirow{5}{*}{ Condição no domicílio } & Referência & - & - & - & - \\
\hline & Cônjuge & 1,02 & 0,04 & 0,00 & 2,79 \\
\hline & Filho & $-0,34$ & 0,05 & 0,00 & 0,71 \\
\hline & Outro parente / agregado & $-0,31$ & 0,06 & 0,00 & 0,73 \\
\hline & Não parente & $-0,97$ & 0,28 & 0,00 & 0,38 \\
\hline \multirow{5}{*}{ Grande Região } & Norte & $-0,39$ & 0,05 & 0,00 & 0,68 \\
\hline & Nordeste & $-0,47$ & 0,04 & 0,00 & 0,62 \\
\hline & Sudeste & 0,01 & 0,04 & 0,85 & 1,01 \\
\hline & Sul & 0,07 & 0,05 & 0,15 & 1,08 \\
\hline & Centro-Oeste & - & - & - & - \\
\hline Tem mãe viva & Sim & $-0,08$ & 0,05 & 0,10 & 0,92 \\
\hline Mãe mora no domicílio & Sim & $-0,34$ & 0,05 & 0,00 & 0,72 \\
\hline Filhos de até 5 anos & Sim & 0,97 & 0,05 & 0,00 & 2,63 \\
\hline Já trabalhou antes & Sim & $-3,18$ & 0,03 & 0,00 & 0,04 \\
\hline Nem-nem no domicílio & Sim & 2,13 & 0,03 & 0,00 & 8,40 \\
\hline \multirow{4}{*}{ Crianças no domicílio } & 0 & - & - & - & - \\
\hline & 1 & $-0,27$ & 0,04 & 0,00 & 0,76 \\
\hline & 2 & $-0,30$ & 0,05 & 0,00 & 0,74 \\
\hline & 3 ou mais & $-0,31$ & 0,08 & 0,00 & 0,73 \\
\hline
\end{tabular}

Nota: $\beta$ é o estimador e $C V(\beta)$ representa o coeficiente de variação do estimador.

Fonte: Elaboração dos autores a partir da Pesquisa Nacional por Amostra de Domicílios (2004). 
Tabela A8

Resultados Modelo Logit para o total de jovens nem-nem - Brasil - 2014

\begin{tabular}{|c|c|c|c|c|c|}
\hline \multicolumn{2}{|c|}{ Coeficiente } & $\beta$ & $|\mathrm{CV}(\beta)|$ & p-valor & $\exp (\beta)$ \\
\hline \multicolumn{2}{|c|}{ Intercepto } & $-0,28$ & 0,10 & 0,01 & 0,76 \\
\hline \multirow{2}{*}{ Sexo } & Homem & - & - & - & - \\
\hline & Mulher & 0,24 & 0,03 & 0,00 & 1,27 \\
\hline \multirow{2}{*}{ Cor ou raça } & Branco & - & - & - & - \\
\hline & Não-branco & 0,07 & 0,03 & 0,02 & 1,07 \\
\hline \multirow{6}{*}{ Nível de instrução } & Até EF incompleto & - & - & - & - \\
\hline & EF comp. & $-0,47$ & 0,05 & 0,00 & 0,63 \\
\hline & EM incompleto & $-1,18$ & 0,05 & 0,00 & 0,31 \\
\hline & EM completo & 0,26 & 0,04 & 0,00 & 1,29 \\
\hline & ES incompleto & $-2,63$ & 0,09 & 0,00 & 0,07 \\
\hline & ES completo & 0,25 & 0,07 & 0,00 & 1,29 \\
\hline \multirow{3}{*}{ Faixa etária } & 15 a 17 anos & $-2,27$ & 0,05 & 0,00 & 0,10 \\
\hline & 18 a 24 anos & 0,03 & 0,03 & 0,26 & 1,04 \\
\hline & 25 a 29 anos & - & - & - & - \\
\hline \multirow{5}{*}{$\begin{array}{l}\text { Quintos de rendimento domiciliar } \\
\text { per capita (em salário-mínimo) }\end{array}$} & $1^{\circ}$ quinto & 1,45 & 0,06 & 0,00 & 4,27 \\
\hline & $2^{\circ}$ quinto & 1,22 & 0,06 & 0,00 & 3,37 \\
\hline & $3^{\circ}$ quinto & 0,78 & 0,06 & 0,00 & 2,18 \\
\hline & $4^{\mathrm{o}}$ quinto & 0,43 & 0,06 & 0,00 & 1,54 \\
\hline & $5^{\circ}$ quinto & - & - & - & - \\
\hline \multirow{5}{*}{ Condição no domicílio } & Referência & - & - & - & - \\
\hline & Cônjuge & 0,51 & 0,04 & 0,00 & 1,66 \\
\hline & Filho & $-0,33$ & 0,05 & 0,00 & 0,72 \\
\hline & Outro parente / agregado & $-0,60$ & 0,06 & 0,00 & 0,55 \\
\hline & Não parente & $-0,91$ & 0,54 & 0,09 & 0,40 \\
\hline \multirow{5}{*}{ Grande Região } & Norte & $-0,43$ & 0,06 & 0,00 & 0,65 \\
\hline & Nordeste & $-0,28$ & 0,05 & 0,00 & 0,75 \\
\hline & Sudeste & 0,08 & 0,05 & 0,11 & 1,08 \\
\hline & Sul & 0,07 & 0,06 & 0,23 & 1,08 \\
\hline & Centro-Oeste & - & - & - & - \\
\hline Tem mãe viva & Sim & $-0,05$ & 0,06 & 0,37 & 0,95 \\
\hline Mãe mora no domicílio & Sim & $-0,38$ & 0,05 & 0,00 & 0,69 \\
\hline Filhos de até 5 anos & Sim & 1,31 & 0,05 & 0,00 & 3,71 \\
\hline Já trabalhou antes & Sim & $-3,27$ & 0,04 & 0,00 & 0,04 \\
\hline Nem-nem no domicílio & Sim & 2,07 & 0,03 & 0,00 & 7,96 \\
\hline \multirow{4}{*}{ Crianças no domicílio } & 0 & - & - & - & - \\
\hline & 1 & $-0,42$ & 0,04 & 0,00 & 0,66 \\
\hline & 2 & $-0,43$ & 0,06 & 0,00 & 0,65 \\
\hline & 3 ou mais & $-0,48$ & 0,11 & 0,00 & 0,62 \\
\hline
\end{tabular}

Nota: $\beta$ é o estimador e CV ( $\beta$ ) representa o coeficiente de variação do estimador.

Fonte: Elaboração dos autores a partir da Pesquisa Nacional por Amostra de Domicílios (2014). 
Tabela A9

Resultados Modelo Logit para o total de jovens nem-nem- Brasil - 2015

\begin{tabular}{|c|c|c|c|c|c|}
\hline \multicolumn{2}{|l|}{ Coeficiente } & $\beta$ & $|\mathrm{CV}(\beta)|$ & p-valor & $\exp (\beta)$ \\
\hline \multicolumn{2}{|l|}{ Intercepto } & $-0,26$ & 0,10 & 0,01 & 0,77 \\
\hline \multirow{2}{*}{ Sexo } & Homem & - & - & - & - \\
\hline & Mulher & 0,21 & 0,03 & 0,00 & 1,23 \\
\hline \multirow{2}{*}{ Cor ou raça } & Branco & - & - & - & - \\
\hline & Não-branco & 0,06 & 0,03 & 0,03 & 1,07 \\
\hline \multirow{6}{*}{ Nível de instrução } & Até EF incompleto & - & - & - & - \\
\hline & EF comp. & $-0,32$ & 0,04 & 0,00 & 0,73 \\
\hline & EM incompleto & $-1,17$ & 0,05 & 0,00 & 0,31 \\
\hline & EM completo & 0,40 & 0,04 & 0,00 & 1,50 \\
\hline & ES incompleto & $-2,65$ & 0,09 & 0,00 & 0,07 \\
\hline & ES completo & 0,29 & 0,07 & 0,00 & 1,34 \\
\hline \multirow{3}{*}{ Faixa etária } & 15 a 17 anos & $-2,50$ & 0,05 & 0,00 & 0,08 \\
\hline & 18 a 24 anos & 0,02 & 0,03 & 0,61 & 1,02 \\
\hline & 25 a 29 anos & - & - & - & - \\
\hline \multirow{5}{*}{$\begin{array}{l}\text { Quintos de rendimento domiciliar per } \\
\text { capita (em salário-mínimo) }\end{array}$} & $1^{\circ}$ quinto & 1,56 & 0,06 & 0,00 & 4,75 \\
\hline & $2^{\circ}$ quinto & 1,24 & 0,06 & 0,00 & 3,45 \\
\hline & $3^{\circ}$ quinto & 0,96 & 0,06 & 0,00 & 2,61 \\
\hline & $4^{\circ}$ quinto & 0,41 & 0,06 & 0,00 & 1,51 \\
\hline & $5^{\circ}$ quinto & - & - & - & - \\
\hline \multirow{5}{*}{ Condição no domicílio } & Referência & - & - & - & - \\
\hline & Cônjuge & 0,46 & 0,04 & 0,00 & 1,58 \\
\hline & Filho & $-0,31$ & 0,05 & 0,00 & 0,74 \\
\hline & Outro parente / agregado & $-0,69$ & 0,06 & 0,00 & 0,50 \\
\hline & Não parente & $-0,94$ & 0,46 & 0,04 & 0,39 \\
\hline \multirow{5}{*}{ Grande Região } & Norte & $-0,49$ & 0,05 & 0,00 & 0,61 \\
\hline & Nordeste & $-0,33$ & 0,05 & 0,00 & 0,72 \\
\hline & Sudeste & 0,01 & 0,05 & 0,91 & 1,01 \\
\hline & Sul & 0,04 & 0,05 & 0,50 & 1,04 \\
\hline & Centro-Oeste & - & - & - & - \\
\hline Tem mãe viva & Sim & $-0,02$ & 0,06 & 0,79 & 0,98 \\
\hline Mãe mora no domicílio & Sim & $-0,38$ & 0,04 & 0,00 & 0,68 \\
\hline Filhos de até 5 anos & Sim & 1,14 & 0,05 & 0,00 & 3,14 \\
\hline Já trabalhou antes & Sim & $-3,16$ & 0,04 & 0,00 & 0,04 \\
\hline Nem-nem no domicílio & Sim & 2,04 & 0,03 & 0,00 & 7,73 \\
\hline \multirow{4}{*}{ Crianças no domicílio } & 0 & - & - & - & - \\
\hline & 1 & $-0,40$ & 0,04 & 0,00 & 0,67 \\
\hline & 2 & $-0,42$ & 0,06 & 0,00 & 0,66 \\
\hline & 3 ou mais & $-0,17$ & 0,11 & 0,13 & 0,84 \\
\hline
\end{tabular}

Nota: $\beta$ é o estimador e CV $(\beta)$ representa o coeficiente de variação do estimador.

Fonte: Elaboração dos autores a partir da Pesquisa Nacional por Amostra de Domicílios (2015). 


\section{Apêndice}

Documentação das variáveis do modelo Logit a partir dos microdados da PNAD

\section{Jovem Nem-Nem:}

Sim:

Até 2006: V0602 = 4 e (V4705 = 2 ou V4704 = 2)

2007 em diante: $\mathrm{V} 0602=4$ e $(\mathrm{V} 4805=2$ ou V4704 = 2)

Não: complemento

V0602 $=4-$ Frequenta creche ou escola, NÃO

V4705 = 2 ou V4805 = 2 - Condição de ocupação na semana de referência, DESOCUPADAS

V4704 = 2 - Condição de atividade na semana de referência, NÃO ECONOMICAMENTE ATIVAS

\section{Jovem Nem-Nem Desocupado:}

Sim:

Até 2006: V0602 = 4 e $(\mathrm{V} 4705=2)$

2007 em diante: $\mathrm{V} 0602=4$ e $(\mathrm{V} 4805=2)$

Não: complemento

V0602 $=4-$ Frequenta creche ou escola, NÃO

V4705 $=2$ ou V4805 = 2 - Condição de ocupação na semana de referência, DESOCUPADAS

\section{Nem-Nem Inativo:}

Sim: V0602 = 4 e $($ V4704 = 2)

Não: complemento

V0602 $=4-$ Frequenta creche ou escola, NÃO

V4704 = 2 - Condição de atividade na semana de referência, NÃO ECONOMICAMENTE ATIVAS

Sexo:

Homem: V0302 $=2$

Mulher: V0302 $=4$

V0302 - Sexo

\section{Cor ou Raça:}

Branco: V0404 = 2

Não branco: V0404 $\neq 2$

V0404 - Cor ou raça

\section{Nível de Escolaridade:}

Ensino Fundamental incompleto: V4745 $=1$ ou 2

Ensino Fundamental completo: V4745 = 3

Ensino Médio incompleto: V4745 = 4

Ensino Médio completo: V4745 = 5

Ensino Superior incompleto: V4745 = 6

Ensino Superior completo: V4745 = 7

Não determinado: V4745 = 8

V4745 - Nível de instrução mais elevado alcançado 


\section{Faixa Etária:}

15 a 17 anos: $15 \leq \mathrm{V} 8005 \leq 17$

18 a 24 anos: $18 \leq \mathrm{V} 8005 \leq 24$

25 a 29 anos: $25 \leq \mathrm{V} 8005 \leq 29$

V8005 - Idade na data de referência

\section{Quintos de Rendimento Domiciliar Per Capita:}

1) Randomizar a base para retirar efeito da ordenação geográfica

2) Ordenação da base pela V4621

$1^{\circ}$ quinto: peso acumulado $\leq 20 \%$

$2^{\circ}$ quinto: $20 \%<$ peso acumulado $\leq 40 \%$

$3^{\circ}$ quinto: $40 \%<$ peso acumulado $\leq 60 \%$

$4^{\circ}$ quinto: $60 \%<$ peso acumulado $\leq 80 \%$

$5^{\circ}$ quinto: $80 \%<$ peso acumulado $\leq 100 \%$

Rendimento domiciliar per capita - V4621

Peso da pessoa - V4729

\section{Condição na Família:}

Pessoa de referência: V0402 = 1

Cônjuge: V0402 = 2

Filho: V0402 = 3

Outro parente / agregado: V0402 $=4$ ou 5

Não parente: V0402 = 5, 6 ou 7

Condição na família - V0402

\section{Grandes Regiões:}

Norte: $11 \leq \mathrm{UF} \leq 17$

Nordeste: $21 \leq \mathrm{UF} \leq 29$

Sudeste: $31 \leq \mathrm{UF} \leq 35$

Sul: $41 \leq \mathrm{UF} \leq 43$

Centro-Oeste: $50 \leq \mathrm{UF} \leq 53$

Unidade da Federação - UF

\section{Tem Mãe Viva:}

Sim: V0405 = 1

Não: complemento

Tem mãe viva - V0405

\section{Mãe Mora no Domicílio:}

Sim: V0406 = 1

Não: complemento

Mãe mora no domicílio - V0406 


\section{Tem Filho de Até 5 anos (para mulheres):}

1) variável auxiliar MTOTA (tem ou teve algum filho, para mulheres):

Sim: V4735 = 1 e V1101 = 1 e $(V 1141 \neq 99$ e V1142 $\neq 99$ e V1151 $\neq 99$ e V1152 $\neq 99$ e V1161 $\neq 99$ e V1162 $\neq 99)$ e $(\mathrm{V} 1141+\mathrm{V} 1142+\mathrm{V} 1151+\mathrm{V} 1152+\mathrm{V} 1161+\mathrm{V} 1162>=1)$

Não: complemento

2) Tem filho de até 5 anos

Sim: MTOTA $=1$ e $(V 1141+V 1142+V 1151+V 1152>0)$ e $((V 1182 \geq$ ano-5 $)$ ou $(V 1182=$ ano-6 e $10 \leq \mathrm{v} 1181$ e v1181 $<=12)$ )

Não: complemento

\section{Já Trabalhou Antes:}

Sim: $1 \leq$ V9891 $\leq 7$

Não: complemento

Faixa de idade em que começou a trabalhar - V9891

\section{Outro Nem-Nem no Domicílio:}

Sim: soma (NEM-NEM) agrupado por V0102, V0103 > 1

Não: complemento

NEM-NEM conforme definido acima

Número de controle - V0102

Número de série - V0103

(V0102 e V0103 conjuntamente identificam domicílio)

\section{Crianças no Domicílio:}

1) Define variável criança $=1$ se V8005 $\leq 5$

2) crianças = soma (criança) agrupado por V0102, V0103

Zero: crianças $=0$

Uma: crianças $=1$

Duas: crianças $=2$

Três ou mais: crianças $\geq 3$

V8005 - Idade na data de referência

Número de controle - V0102

Número de série - V0103

(V0102 e V0103 conjuntamente identificam domicílio) 